REVISTA DE DERECHO UNED, NÚM. 11, 2012

\title{
BRAQUIGRAFÍA DE LAS CITAS DE DIGESTO EN LOS MANUSCRITOS DE LOS SIGLOS XI AL XVI
}

\author{
ABBREVIATIONS IN THE CITATIONS OF THE DIGEST \\ OF JUSTINIAN IN THE MANUSCRIPTS OF THE ELEVENTH \\ TO THE SIXTEENTH CENTURIES
}

FERNANDo REINOSO BARBERo

Catedrático de la Universidad Complutense de Madrid

Resumen: Este estudio proporciona la información fundamental para poder interpretar adecuadamente las diversas formas de citar los pasajes de Digesto que se emplean por las cinco generaciones de glosadores de los siglo XI al XIII, por los comentaristas de los siglos XIII al XV y los humanistas a partir del siglo XVI.

Abstract: This study provides key information to properly interpret the various ways used in order to quote passages of the Digest by the five generations of glossators from the eleventh to the thirteenth century, the commentators from the thirteenth to the fifteenth century and the humanists from the sixteenth century onwards.

Palabras clave: Derecho romano medieval, citas de los textos de Digesto, glosadores, comentaristas, postglosadores, humanistas, glosa, Bolonia, Digestum vetus, Digestum novum, Infortiatum, Corpus Iuris Civilis, siglas y abreviaturas en Digesto.

Keywords: Medieval Roman Law, glossators, commentators, postglossators, glossa, Bologna, Digestum vetus, Digestum novum, Infortiatum, Corpus Iuris Civilis, to quote passages of the Digest, Sigla and Abbreviations in the Digest.

Recepción original: 25/07/2012

Aceptación original: 27/07/2012 
Sumario: I. Causas endógenas que determinan el modo de citar; II. Métodos de correspondencia biunívoca en la elaboración de las citas; II.1. Initium mediante la adición de palabras; II.2. Initium mediante orden en secciones de igual rango; III. Braquigrafía de los elementos que forman las citas de Digesto; III.1. «ff.» como aféresis

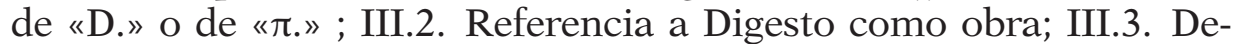
claración de títulos y rúbricas; III.4. Initium de leyes o fragmentos; III.5. Parágrafos.

\section{CAUSAS ENDÓGENAS QUE DETERMINAN EL MODO DE CITAR}

No existe un único criterio determinante del contenido de las citas de Digesto. La razón última de la falta de unanimidad radica sobre todo en el gran número de juristas, distribuidos en varios siglos, que las utilizan tanto como emisores como receptores. Pero hay otras razones que influyen en mayor o menor medida en las técnicas de su elaboración. Una de ellas es el lugar en el que se debía escribir la cita, pues no era lo mismo citar en una glosa interlineal que en una marginal en la que se disponía de mayor espacio. A medida que éste aumenta también lo hacen las extensiones de las citas, de ahí que en los libros de comentarios pandectarum tan propios del renacimiento se llegara a incluir en las citas incluso los datos de la inscripción del fragmento. Compárese, por ejemplo, dos citas de Digesto realizadas en glosas del aparato accursiano como

$$
\begin{aligned}
& \text {.J.e.l\$ait Senatus }{ }^{1} \text { (= D. 5,3,20,7) } \\
& \text { ut Š.titu.j.l.ij. }{ }^{2} \text { (= D. 26,2,2) }
\end{aligned}
$$

con otra de Antonio Agustín en la que se alterna el número con el initium del parágrafo y se recoge además el nombre del jurista y la obra:

c. is qui in puteum 11. §. 7. an ignoscitur D. quod vi aut clam. ex lib. 72. Ulpiani ad edictum ${ }^{3}$ (= D. 43,24,11,7)

También intervienen en la forma en la que se hace la cita los manuscritos de la que se toma, que no son los mismos en las distintas

${ }^{1}$ Cfr. en Digestum Vetus glosa «d», exacta est, a D. 5,3,20,15.

${ }^{2}$ Cfr. en Infortiatum glosa «c», \& a quibus, a D. 26,3,1.

${ }^{3} \mathrm{Cfr}$. Antonius Augustinus, Emendationum, et Opinionum libri quatuor, Venetiis 1543 =Lugduni 1560. He utilizado la edición recogida por Everardi Ottonis, Thesausurus juris romani, IV, Trajecti ad Rhenum, 1733, 1452. Cfr. ReINOso-BARBERo, El estudio de las geminaciones jurisprudenciales de Antonius Augustinus, en RGDR 18, 2012, §412181, 11. 
épocas. Hay manuscritos que carecen por completo de números, otros que numeran sólo los libros, o éstos y los títulos o incluso también los fragmentos. Hay una evolución clara desde el siglo XII al XVI y desde aquí en adelante ${ }^{4}$. Tal circunstancia resulta capital. De ella derivan a su vez otras que facilitan que las escuelas y sub escuelas de juristas desarrollen modos y usos para declarar las fuentes, muy vinculados a las características del material que cada una de ellas dispone. Debe tenerse en cuenta que hablamos de un periodo que incluye a las cinco generaciones de glosadores, casi a otras tantas de comentaristas y a los humanistas. En consecuencia, desde la época de Pepo de Bolonia (siglo XI) hasta el último de los Godofredo (siglos XVI-XVII). Por citar sólo a unos pocos representantes de cada uno de esos periodos, en el primero sobresalen Irnerio, Bulgaro, Martino Gosia, Jacobo de Boragine, Hugo de Ravennate, Burgundio, Azo o Azón y Accursio ${ }^{5}$; en el segundo destacan Cino de Pistoia, Bártolo de Saxoferrato, Raimundo Lulio, Guillermo Durante, Jacobo Butrigario, Juan Faber, Pedro de Bellapertica, Alberico, Baldo de Ubaldis, Rafael Fulgosio, Decio, Alejandro ab Alexandro, Hadriano Mario y Francisco Aretino ; y en el tercero: Antonio Agustín, Policiano, Torelli, Metelo, Haloandro, Andrés Alciato, Cuyacio ${ }^{7}$, Juan de Coras, Prateio, Donello, Dionisio y su hijo Jacobo Godofredo.

Esa multitud de citadores, conscientes de que están provistos de códices de Digesto no coincidentes entre sí, es lo que determina que, a falta de otras pautas mejores, se elija el comienzo del texto como soporte angular de la cita. No es un método «absurdo e incomprensible» ni mucho menos "un yugo pedante», como se ha sugerido irreflexivamente en alguna ocasión, pues entonces no era posible the

${ }^{4}$ Con carácter general se pueden transponer las citas más elementales a las formas modernas con la ayuda de los índices de NicolinI \& D'AMICO, Indices corporis iuris civilis iuxta vetustiores editiones cum criticis collatas, 5 vols., Milán, 1964-1967; y de OchoA \& Diez, Indices titulorum et legum Corporis iuris civilis, Roma, 1965.

${ }^{5}$ Una relación casi completa puede verse en Lange, Römisches Recht im Mittelalter: die Glossatoren, I, Munich, 1997, 151 y ss. Cabría añadir a Rogerio (pp. 192 ss.), Alberico (pp. 200 ss.), Placentino (pp. 207 ss.), Henrico (pp. 214 ss.), Juan Basiano (pp. 215 ss.), Cypriano (pp. 235 ss.), Vacario (pp. 246 ss.), Balduino (pp. 286 ss.), Simón Vicentino (pp. 310 ss.), etc.

${ }^{6}$ Lange \& Kriechbaum, Römisches Recht im Mittelalter:II. Die Kommentatoren, Munich, 2007, 435 y ss., estudian muchos más: Jacobo de Arena (pp. 435 ss.), Dino de Rossoni (pp. 445 ss.), Juan Blanosco (pp. 461 ss.), Alberto Gandino (pp. 468 ss.), los numerosos comentaristas napolitanos (pp. 496 ss.), franceses (pp. 518 ss.) y de los siglos XIV (pp. 593 ss.) y XV (pp. 795 ss.), etc.

${ }^{7}$ COMA FORT, La editio Cuiaciana de 1566, en «Revista catalana d'historia del dret», 14, 2009, 695 ss; e ID, Indice comentado de las colecciones de fuentes del Corpus iuris civilis, Pamplona 2008. 
simple and rational method of numbering the book, title, and the law ${ }^{8}$. Tampoco puede decirse que constituya una técnica irracional pues quienes así lo creen no siempre valoran que su utilización ha sido tan conveniente que se prolonga hasta el siglo XIX y que, aún hoy, prevalece entre los canonistas ${ }^{9}$.

El hecho constatado es que sólo a partir del año 1529, a medida que se estabiliza la topografía de la distribución de fragmentos en Digesto y que se intenta consolidar la numeración de éstos, beneficiada por las ediciones impresas, cobra sentido el procedimiento de citar mediante números que, en consecuencia, comienza a arraigar de forma paulatina. Antes de ello no es factible sencillamente porque ni se han generalizado aún los Digestos con numeración ni los existentes cuentan con garantías de concordar con los demás.

Es más, en la época de los glosadores e incluso en la de los comentaristas ${ }^{10}$, consta la voluntad explícita de evitar en lo posible citar los números tanto de las secciones grandes (las rúbricas) como de las pequeñas (fragmentos y parágrafos) ${ }^{11}$. La opinión generalizada es que es más sencillo incurrir en un error de cita cuando se utilizan los números. Contra lo que cabe imaginar prima facie, en realidad, para ellos es más fácil recordar el comienzo de los títulos que los números. Las palabras, las frases, disponen en el lenguaje humano de un significado reconocible ${ }^{12}$ frente a la insensibilidad expresiva de

${ }^{8}$ GIBBON, The history of the decline and fall of the Roman empire, Volumen 5, Londres 1821, 315 nt «a», es uno de los críticos del método empleado por los glosadores para citar las obras justinianeas; método que demuestra claramente desconocer cuando afirma "The civilians of the darker ages, have established an absurd and incomprehensible mode of quotation, which is supported by authority and custom. In their references to the Code, the Pandects, and the Institutes, they mention the number, not of the boot but only of the law and content themselves with reciting the first words of the Title to which it belongs: and of these titles there are more than a thousand Ludewig, (Vit. Justiniani, p. 268,) wishes to shake off this pedantic yoke; and I have dared to adopt the simple and rational method of numbering the book, title, and the law».

${ }^{9}$ Una excepción que acepta esta contradictio in terminis la representa KANTOROWICZ, Die Allegationen im späteren Mittelalter, en «Archiv fur Urkundenforschung», 13, 1935, 16, cuando él mismo reconoce la utilidad que tuvo y sigue teniendo el método: "Es ist das eine irrationale aber manchmal bequeme Allegationsweise, die bei den Romanisten bis ins 19. Jh. herrschte und bei den Kanonisten noch heute herrscht".

${ }^{10}$ Lange \& Kriechbaum, Römisches Recht im Mittelalter:II. Die Kommentatoren, cit., 6, a propósito del método de los comentaristas, se remiten al tratado de JoHANN Baptista Caccialupus, De modo studendi in utroque iure, 1467.

${ }^{11}$ Grossfeld, Zeichen und Zahlen im Recht: Zahlen in Rechtsgeschichte und Rechtsvergleichung, 1995, Tübingen, 57 y 147 estudia el empleo de los números en derecho romano, 59 en la edad media, y 97 en el Corpus Iuris.

12 Sobre las formas de aprendizaje en la edad media y en el renacimiento Vid. 
los números. En aquellos períodos históricos, y prácticamente hasta el final de la Edad Media, los números existentes en algunos manuscritos de Digesto son griegos o, con más frecuencia, latinos. Los primeros a menudo son desconocidos para los copistas que, como luego veremos, en más de una ocasión transponen los números griegos en forma de garabatos irreconocibles. Esto sucede desde el siglo IX y se prolonga hasta casi el final de la edad media, por ejemplo en el ms. Berlinés, Lat. fol. n. 269 («R» en la nomenclatura de Mommsen porque fue comprado a la Biblioteca Rosnyana por la Biblioteca pública de Berlín) pues, como traduce Bartol ${ }^{13}$, las abreviaturas numerales griegas están escritas delante de cada una de los fragmentos (es decir, D. 1,3,3-36. 5,12,16. 6,9.10. 7,2.3) y están tan corruptas que parece que el copista no entiende su significado y se limita a copiarlos del arquetipo ${ }^{14}$. Los segundos, los números latinos, no siempre son sencillos de recordar sobre todo cuando expresan cifras largas, por lo que la doctrina ${ }^{15}$ los responsabiliza de producir muchos errores de escritura y de lectura, con la consiguiente imposibilidad de localizar el texto citado.

A ello se suma una obviedad comprobada con reiteración: cuando los números están presentes en los manuscritos de Digesto casi siempre guardan un porcentaje relevante de diferencias con el resto de ejemplares. Se observa este hecho no sólo en las citas, que quizás los copistas pudieron corromper, sino también en las distintas formas que hay de numerar. Mommsen constata múltiples clases de errores que suelen producirse en la numeración de los códices, en los que de ordinario conviven números u ordinales añadidos por varias manos, o se contabiliza mal algún caput que de forma indebida se une o se separa de los precedentes pero, en ambos casos, con desviaciones que afectan al orden asignado a los fragmentos posteriores ${ }^{16}$.

Johannes JacoBus CANIS, De modo studendi in utroque iure, Brünn, apud: Conrad Stahel y Mathias Preunlein, 1488; y JoAnnes CAmers, De modo studendi in utroque iure epistola, Roma, apud: Eucharius Silber, 1491.

${ }^{13}$ Bartol, Uersio Praefationis Editionis Maioris, Madrid, 2004, 91.

${ }^{14}$ Mommsen, Praefatio editionis maioris, Digesta Iustiniani Augusti, Berolini, 1870 (en adelante Praefatio), XXXXV: «praescribuntur singulis legibus passim (scilicet 1, 3, 3-36. 5, 12.16. 6, 9.10.7,2.3) notae numerales Graecae ita corruptae, ut appareat librarium earum significationem non assecutum eas ex archetypo repetiuisse».

${ }^{15}$ Kantorowicz, Die Allegationen im späteren Mittelalter, cit., 16, es de esta opinión y atribuye a los números latinos la paternidad de no pocos deslices.

${ }^{16}$ Mommsen, Praefatio, cit., $\mathrm{X}$ dice «... reliqui utriusque linguae auctores utuntur quidem numeris, tantopere autem ii numeri inter se differunt non tantum in singularibus citationibus, quae potuerunt a librariis corrumpi, sed ipsa numerandi ratione, ut alios numeros ab aliis auctoribus exemplaribus suis adscriptos esse appareat capite aliquo male, ut fit, siue adiuncto praecedentibus siue inde seiuncto». 
Basta pensar en la divergencia que todavía guardan entre sí las numeraciones de algunas Vulgatas impresas posteriores, o las que existen entre las de éstas y la disposición de los fragmentos florentinos. Hoy debe resultarnos fácil comprender las patologías descritas si tenemos en cuenta que la propia edición crítica mommseniana cobija numeraciones distintas que expresa mediante paréntesis ${ }^{17}$. En algunos títulos de la editio maior de Digesto hay incluso no uno sino varios fragmentos de diferencia entre dos numeraciones. Por ejemplo en D. 36,1: la inscripción de D. 36,1,15 (Ulpianus libro quarto fideicommissorum) falta en $F$, por lo que el fragmento figura unido al anterior. $\mathrm{Al}$ ser reconstruida por Cuyacio ${ }^{18}$, se separan ambos textos y aumenta el número, por lo que el fragmento siguiente pasa a ser numerado en la edición crítica como D. 36,1,16(15) y así hasta 44(43). El fragmento 45 es reconstruido completamente, por lo que se añade un segundo número del que resulta D. 36,1,46(44) hasta 83(81).

Por tanto y en definitiva, los números no son en esa época el mejor remedio al problema que representa la necesidad de citar con precisión fuentes jurídicas inarticuladas. En otro caso es seguro que se hubieran utilizado, pues no cabe esperar cosa distinta de talentos como los de, por ejemplo, Azo o Bártolo, por mencionar sólo a dos actores de dos épocas ${ }^{19}$.

Los glosadores son los primeros que se enfrentan científicamente a los inconvenientes que registra la cita de Digesto que, por lo de-

${ }^{17}$ CoING, Handbuch der Quellen und Literatur der neueren europäischen Privatrechtsgeschichte: 1. Mittelalter (1100-1500): Die gelehrten Rechte und Die Gesetzgebung, München, 1973. MARGADANT, La segunda vida del derecho romano, Mexico, 1986, 105, subraya precisamente el paradigma constituido por la dualidad de numeración que se presenta en algunas partes de las ediciones científicas modernas de las obras que integran el Corpus Iuris, no sólo Digesto. A este respecto afirma «Un típico reflejo de esta capacidad de memorizar es la forma de citar el Corpus Iuris antes de que la imprenta y la paciente labor de eruditos editores hubiera hecho posible una edición estandarizada del Corpus Iuris, era imposible, desde luego, numerar de manera uniforme los títulos (aún en la edición fundamental actual-Mommsen c.a- encontramos cierto dualismo, indicado con paréntesis, por ejemplo en algunos títulos de Codex II, VIII y X-XII, y de las citas (leyes o "fragmentos" dentro de cada título) ... y las citas fueron indicadas por las primeras palabras del título y del fragmento, lo cual complica ligeramente al investigador moderno el análisis de las glosas medievales (aunque dispongamos de índices, que nos ayudan para esto). Conviene recordar al respecto, que los estudiosos medievales trabajaron en general mucho más en la profundidad, mientras que nosotros vivimos más bien en un ambiente de amplitud; se basaron en pocos libros, que trataron de conocer con todo detalle.»

${ }^{18}$ KRÜGER, Corpus Iuris Civilis ${ }^{24}$ (en adelante CIC), I, Hildesheim, 1988, 564 nt. 27.

${ }^{19} \mathrm{PACE}$, Iterum homines querebant de legibus. Una nota sulla riemersione dei Digesti nel medievo, en «Rivista Internazionale del Diritto Comune» 3, 1992, 221-229. 
más, son muy similares a los del resto de las obras justinianeas ${ }^{20}$. Los resuelven mediante la práctica de la única forma que quizás resulta viable: llamar a los textos por sus primeras palabras o initium. Pronto se comprueba que unas pocas palabras permiten identificar con exactitud una fuente cualquiera. El precio es el aparente esfuerzo memorístico; precio que no es demasiado alto pues, como es sabi$\mathrm{do}^{21}$, el entrenamiento de la memoria es un objetivo primordial de la enseñanza medieval, y su alta eficacia es asumida por la literatura jurídica ${ }^{22}$.

\section{MÉTODOS DE CORRESPONDENCIA BIUNÍVOCA EN LA ELA- BORACIÓN DE LAS CITAS}

Los glosadores desarrollan un procedimiento de cita completamente nuevo. Es verdad que antes de ellos hay usos en las citas de Digesto que prescinden de los números y utilizan en su lugar las inscripciones secundarias del index titulorum, o la posición de la fuente o el nombre del jurista autor de la misma ${ }^{23}$. Es el caso, por ejemplo, de Juliano, quizás el último de los antecessores ${ }^{24}$, del que conocemos

${ }^{20}$ Colli, Un testimone della Lectura Digesti veteris di Baldo degli Ubaldi datato 1387, en «Ius Commune» 27, 2000, 407-422; KUTTNER, The revival of jurisprudence, en Renaissance and renewal in the twelfth century, Oxford, 1982, 299-323; MoR, Il Digesto nell'età preirneriana e la formazione della Vulgata, en «Scritti di storia giuridica altomedievale>, Pisa, 1977, 83-234; MüLLER, The recovery of Justinians Digest in the middle ages, en "Bulletin of Medieval Canon Law» 20, 1990, 3-30; RadDING, Vatican Latin 1406, Mommsens Ms. S. and the reception of the Digest in the Middle Ages, en ZSS 110, 1993, 501-551; RICART MARTí, La tradicion manuscrita del Digest en el Occidente medieval a traves del estudio de las variantes textuales, en «AHDE»58, 1987, 5-206; Soetermeer, Due tradizioni testuali francesi dell'Apparatus Digesti Novi di Accursio, en «Rivista Internazionale di Diritto Comune» 8, 1997, 77-127; WaLlinga, The continuing story of the date and the origin of the Codex Florentinus, en «Subseciva Groningana» 5, 1992, 7-19.

${ }^{21}$ En este sentido vid. Kantorowicz, Die Allegationen im späteren Mittelalter, cit., 16, que recuerda que «die Schulung des Gedächtnisses ein Hauptziel des mittelalterlichen Unterrichts war, und sein hohe Leistungsfähigkeit von der Literatur vorausgesetzt wurde».

${ }^{22}$ RadDing \& Ciaralli, The Corpus Iuris Civilis in the Middle Ages: Manuscripts And Transmission from the Sixth Century to the Juristic Revival (Volumen 147 de «Brill's Studies in Intellectual History») Leiden-Boston 2007, 178-185, a propósito del valor de Digesto en las enseñanzas jurídicas en el siglo XI.

23 Bartol, Uersio Praefationis Editionis Maioris, cit., 9.

${ }^{24}$ Sobre la forma de citar las fuentes por los antecessores, el trabajo esencial es el de Scheltema, L'enseignement de droit des antécesseurs, Lugduni Batavorum, 1970. También ANDRÉs SANTOS \& Signes, La introducción al derecho (Eisagoge) del Patriarca Focio, Valladolid, 2007, 57 y ss. ofrecen una síntesis magnífica sobre la utilización 
su forma de citar Digesto a través del Epitome Iuliani ${ }^{25}$ y de los manuscritos de su Apéndice «B»: Dictatum de consiliariis y la Collectio de tutoribus. Por ejemplo, con la cita

ut est relatum in primo libro Protorum titulo secundo digesto secundo ${ }^{26}$

Juliano se refiere a D. 1,2,2,33. Sin embargo no es éste el método que siguen los glosadores. Ellos optan por un procedimiento de mayor precisión, compatible con una mayor brevedad. Ese mismo texto, D. 1,2,2,33, lo citan así:

\section{ff. de O.J. l. Necessarium \& Et haec omnia}

Los glosadores, como sabemos, parten de una mínima referencia a la rúbrica bajo la que se encuentra la fuente, a la que le añaden su initium y, si fuera necesario, el del parágrafo. Es decir: $f f+l .(+\S)$. Este proceso lo despliegan dentro de un criterio de economía que comienza con la abreviación o, en casos extremos, con la reducción a siglas de la rúbrica, y continúa con la utilización de las palabras indispensables del initium del texto.

Si prescindimos de las rúbricas, Digesto cuenta con 21.082 textos entre fragmentos y parágrafos (20.945 son latinos, 128 griegos y 9 mixtos $\left.{ }^{27}\right)$. El 95\% de ellos aproximadamente -por tanto, unos 20.000 - tienen un initium con tres o menos palabras (v. $g r$. D. 29,5,1,1 = Domini appellatione continetur), y más de la mitad de los initia sólo dispone de una o dos palabras (v. gr. 29,2,94 = Qui superstitis).

A partir de los glosadores se instauran dos métodos igualmente válidos para la construcción del initium de cada fragmento y de cada

de las colecciones escolásticas de los antecessores justinianeos en las universidades de Constantinopla y Beirut, desde la información de los escolios incorporados a las colecciones jurídicas a partir del siglo IX. Sobre el trabajo de los antecessores en las obras del Corpus iuris, vid. MAAS \& KIHN, Exegesis and Empire in the Early Byzantine Mediterranean: Junillus Africanus and the Instituta Regularia Divinae Legis, Tübingen, 2003, 74-75.

${ }^{25}$ KAISER, Die Epitome Iuliani: Beiträge zum römischen Recht im frühen Mittelalter und zum byzantinischen Rechtsunterricht, Frankfurt, 2004; y también, aunque sin referencia ninguna a Digesto, BRIguglio, L' Epitome Iuliani e il Legum Iustiniani imperatoris vocabularium, en «Rivista di Diritto Romano», 1, 2001, en nt 3 recoge un repertorio bibliográfico completo sobre el epitome Iuliani.

${ }^{26}$ Capítulo 88 de los paratitla, cfr. BARTol, Uersio Praefationis Editionis Maioris, cit., 9 nt. 6 y KaISER, Die Epitome Iuliani, cit., 33.

${ }^{27}$ Los nueve initia mixtos, es decir, con palabras latinas y griegas son: Codici-

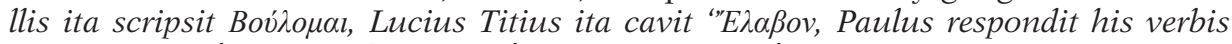

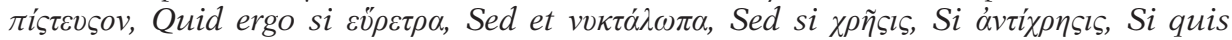

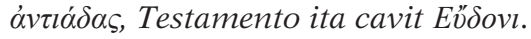


parágrafo. El primero de ellos se asienta en un proceso de adición de las palabras necesarias para que la cita de un texto sea unívoca, mientras que el segundo se conforma con un número de palabras menor que ordena dentro de secciones de igual rango. Estos métodos son los siguientes:

\section{II.1. Initium mediante la adición de palabras}

Es el procedimiento común y primero. Cuando es posible el initium está integrado por una única palabra. Sólo aumenta el número de palabras en la medida que sean necesarias para distinguir un pasaje de otro. Esto es, del comienzo del texto se toma generalmente la primera o las dos primeras palabras, pero a menudo también las palabras tercera, cuarta y quinta ${ }^{28}$. La razón de que haya más o menos palabras obedece casi siempre ${ }^{29}$ a la finalidad que se persigue: el establecer una correspondencia biunívoca entre el initium y el texto citado, de forma que a cada initium le corresponda un único texto y viceversa. Esto se consigue mediante la adición sucesiva de palabras hasta que desaparezca la ambigüedad. Por ejemplo, los parágrafos D. 47,10,15,17 y 47,10,15,18 comienzan ambos por la misma palabra: Abduxisse. A fin de evitar la confusión en la referencia a cualquiera de ellos, se añade a sus respectivos initia la palabra siguiente del comienzo de cada texto, de forma que el primero se cita como Abduxisse videtur y el segundo como Abduxisse autem. Estas segundas palabras son distintas entre sí y no es necesario seguir añadiendo más. Para formar la declaración completa se antepone al initium del parágrafo (§) el del fragmento (l.) y a éste la rúbrica del título (ff.), de forma que la cita de esos dos textos se establece en los siguientes términos:

ff. de iniuriis l. Item apud Labeonem $\S$ Abduxisse videtur (= D. $47,10,15,17)$

ff. de iniuriis l. Item apud Labeonem $\S$ Abduxisse autem (= D. $47,10,15,18)$

Como he dicho ya, la mayoría de los initia cuenta con un mínimo de una palabra y un máximo de cinco. Fuera de esta regla general sólo se encuentran dieciocho pares de textos con un número de palabras en sus initia superior a cinco: nueve pares con seis palabras,

${ }^{28}$ Uno de los primeros en detectar que las citas de los glosadores no superan las cinco palabras es KanTOROWICZ, Die Allegationen im späteren Mittelalter, cit., 16..

${ }^{29}$ Con frecuencia el initium se amplía también a una segunda o tercera palabra en búsqueda de un sentido que facilite recordarla. Esto sucede generalmente cuando los textos comienzan por conjunciones, preposiciones, pronombres o, en general, partículas breves (ut, cum, et, qui, quod, si...). 
cinco pares con siete, tres pares con ocho y un par con diez. Son los siguientes:

6 pals. Si quis negotia aliena gerens indebitum (=D. 3,5,22)

Si quis negotia aliena gerens plus $(=$ D. $3,5,24)$

Is qui rei publicae causa afuturus (=D. 4,6,39)

Is qui rei publicae causa abest $(=\mathrm{D} .4,6,44)$

Si mulier contra senatus consultum intercesserit (=D. 16,1,14)

Si mulier contra senatus consultum Velleianum (=D. 16,1,16,pr.)

Si inter virum et uxorem pactum (=D. $23,4,24)$

Si inter virum et uxorem convenit (=D. 23,4,31)

Papinianus quoque libro septimo responsorum ait (=D. 33,7,12,23)

Papinianus quoque libro septimo responsorum uxori $(=\mathrm{D} .33,7,12,45)$

Idem Celsus libro nono decimo quaestionum (=D. 34,2,19,3)

Idem Celsus libro nono decimo digestorum (=D. 34,2,19,6)

Item sciendum est hanc actionem vel (=D. 39,3,1,13)

Item sciendum est hanc actionem non $(=\mathrm{D} .39,3,1,17)$

Si qua insula in flumine propria (=D. $41,1,65,1)$

Si qua insula in flumine publico (=D. 41,1,65,2)

Interdictum quod vi aut clam per (=D. 43,24,17)

Interdictum quod vi aut clam competere (=D. 43,24,19)

7 pals. Si debitor mulieris dotem sponso promiserit posse (=D. 23,3,80)

Si debitor mulieris dotem sponso promiserit non (=D. 23,3,83)

Sed si duos ex asse heredes scripserit (=D. 28,5,13,5)

Sed si duos ex asse heredes instituerit (=D. 28,5,13,6)

$\mathrm{Si}$ is qui solvendo non est primo (=D. 28,5,56)

$\mathrm{Si}$ is qui solvendo non est servum (=D. 28,5,58)

Hoc senatus consultum non tantum ad urbem (=D. 30,41,6)

Hoc senatus consultum non tantum ad aedes (=D. 30,41,8)

Si ita stipulatus fuero decem aut quinque $(=\mathrm{D} .45,1,12)$

Si ita stipulatus fuero decem aut quindecim (=D. 45,1,109)

8 pals. Sed si priusquam legatum filio solveretur mulier dotem (=D. 33,4,7,1)

Sed si priusquam legatum filio solveretur mulier divertit (=D. 33,4,7,3)

Cum ex pluribus causis debitor pecuniam solvit utriusque (=D. 46,3,97)

Cum ex pluribus causis debitor pecuniam solvit Iulianus (=D. 46,3,103)

Lege Iulia de vi publica tenetur qui arma (=D. 48,6,1)

Lege Iulia de vi publica tenetur qui cum (=D. 48,6,7)

10 pals. Si quis servum iussum decem dare et liberum esse vendiderit (=D. 40,7,3,7)

Si quis servum iussum decem dare et liberum esse operari $(=D .40,7,3,8)$

Se observará que los textos de cada uno de estos pares:

Sólo se diferencian en la palabra final, que oficia de factor dirimente. 
Pertenecen siempre al mismo título de Digesto.

Corresponden invariablemente a una sección de idéntico rango, es decir, en cada par ambos textos o bien son «leyes» o bien ambos son parágrafos.

De no concurrir estos tres factores no sería necesario un initium tan extenso pues se desambigua la cita por medio de la referencia a la rúbrica o, si se trata de un parágrafo, a la «ley» de la que depende. No obstante, en seguida veremos que los glosadores desarrollan un método alternativo que permite reducir considerablemente estos initia sin merma de la exactitud de la cita.

Antes aclararé que este proceso de construcción de las citas requiere identidad, además de en las palabras por las que comienza el texto, en el título y en el rango. Cualquier alteración en éstos evita el ampliar el initium.

Un ejemplo con identidad de palabras iniciales y de rango pero no de título: D.10,3,24 y 41,1,45 tienen en común, además del rango (ambos son «leyes»), un comienzo igual y extraordinariamente extenso de 25 palabras: Communis servus si ex re alterius dominorum adquisierit nihilo minus commune id erit sed is ex cuius re adquisitum fuerit communi dividundo iudicio eam summam. La amplia coincidencia obedece a que se trata de dos textos geminados, aunque la geminación sea irregular pues procede de juristas distintos (el primero es de Juliano libro octavo digestorum y el segundo de Gayo libro septimo ad edictum provinciale). Sin embargo la disparidad en el título permite reducir cada initium de ambos textos a una sola palabra, Communis, con lo que sus citas quedan así:

ff. communi dividundo l. Communis (= D. 10,3,24)

ff. de adquirendo rerum l. Communis (= D. 41,1,45)

Un ejemplo con identidad de palabras iniciales y de título pero no de rango: D.48,5,8 y 48,5,40,7 pertenecen al mismo título D. 48,5 (ad legem Iuliam de Adulteriis) y comienzan además por las mismas palabras: Incesti commune crimen adversus duos simul intentari potest, sin embargo mientras el primero es un fragmento (o «ley») el segundo es un parágrafo, por lo que el initium de ambos puede ser idéntico sin afectar a la precisión de la cita, ya que este último texto incorporará a la suya el initium del fragmento:

ff. ad Legem Iuliam de Adulteriis l. Incesti (= D. 48,5,8)

ff. ad Legem Iuliam de Adulteriis l. Vim passam § Incesti (= D. 48,5,40,7) 


\section{II.2. Initium mediante orden en secciones de igual rango}

Cuando varios fragmentos de una misma subdivisión tienen el mismo initium, los glosadores los diferencian entre sí añadiendo una cifra. La cita de los pasajes de Digesto conduce a encontrar modos alternativos de simplificarla, sobre todo en algunos tipos de glosa en la que materialmente se dispone de muy poco espacio. Sabemos que los textos más problemáticos en este sentido son, naturalmente, los que tienen un initium más extenso. Ahora bien, la razón de su extensión es siempre el pertenecer a la misma sección o subdivisión, en igual rango, dentro de Digesto. Los glosadores convierten el fundamento de esa incómoda amplitud en la causa de su reducción mediante la simple asignación de un ordinal dentro de su sección. Es decir, se reduce el initium y se le añade el número de coincidencia. Con el fin de evitar confusión con otras cifras, ésta tiene dos características:

1. la única o última «i» es reemplazada por una «j» (por ejemplo: $j, i j, i i j, \ldots v i j, v i i j)$.

2. y la cifra se encierra dentro de dos puntos, uno al principio y otro al final (por ejemplo: .j. .ij. .iij. ... .vij. .viij.). El punto inicial se omite cuando es precedido inmediatamente por una abreviatura que lleve un punto (por ejemplo: l.iij.) ${ }^{30}$.

Un ejemplo clásico ${ }^{31}$ de este procedimiento lo proporciona D. 4,2, título en el que hay varios fragmentos que comienzan por la palabra metus, concretamente los números 5,6 y 9. Si se quisiera citar este último-D. 4,2,9- hay dos posibilidades igualmente correctas. Bien aplicar el método básico y ampliar el número de palabras hasta que el initium se distinga con claridad del resto de los fragmentos; en ese caso se citaría:

ff. quod. met. l. metum autem praesentem (= D. 4,2,9)

o bien numerar las apariciones de comienzo similar e indicar, en consecuencia, que se trata de la tercera, mediante la siguiente cita:

ff. quod. met. l. metum .iij. ${ }^{32}$ (= D. 4,2,9).

${ }^{30}$ Kantorowicz, Die Allegationen im späteren Mittelalter, cit., 17.

31 Este ejemplo lo utilizan tanto Thibaut como Hugo; cfr. Thibaut, Über die Arten das Corpus Iuris allegiren zu Romani, cit., 211 y Hugo, Über die Art das Corpus iuris zu zitiren, cit., 217

32 Thibaut, Über die Arten das Corpus Iuris allegiren zu Romani, cit., 211, «... musste man entweder noch mehr anfangsworte schreiben, damit eine scharfe Unterscheidung heraus, mithin so screiben: ff. quod. met. 1. metum autem praesentem 
Es más, este criterio pasa a las generaciones de juristas posteriores que reducen la cita aún más hasta dejarla en $l$. $9 \mathrm{ff}$. quod. met. ${ }^{33}$.

Los glosadores aplican indistintamente el procedimiento reductor tanto a los fragmentos como a los parágrafos ${ }^{34}$. Un ejemplo de los primeros:

ff. de V.S. l. Anniculus amittitur =ff. de V.S. l. Anniculus .j. (= D. 50,16,132)

ff. de V.S. l. Anniculus non =ff. de V.S. l. Anniculus .ij. (= D. 50,16,134) y un ejemplo de los segundos:

ff. de legitimis tutoribus l. Legitimos $\S$ An ergo et provocare $=f f$. de legitimis tutoribus l. Legitimos $\S$ An ergo .j. (= D. 26,4,5,3)

$f f$. de legitimis tutoribus l. Legitimos $\S$ An ergo et in patronis $=f f$. de legitimis tutoribus l. Legitimos $\S$ An ergo .ij. (= D. 26,4,5,4)

Este método sintetiza el initium pero mantiene la correspondencia unívoca entre el texto y la cita. Los textos más beneficiados son los que tienen un initium más extenso. Se puede aplicar a los dieciocho pares de textos antes mencionados, en cuyos initia se alojan entre seis y diez palabras, de forma que éstos quedan reducidos a una, dos o un máximo de tres:

ff. de negotiis gestis l. Si quis negotia .j. (=D. 3,5,22)

ff. de negotiis gestis l. Si quis negotia .ij. (=D. 3,5,24)

ff. ex quibus causis l. Is qui rei .j. (=D. 4,6,39)

ff. ex quibus causis l. Is qui rei .ij. (=D. 4,6,44)

ff. ad SCt Velleianum l. Si mulier .j. (=D. 16,1,14)

ff. ad SCt Velleianum l. Si mulier.ij. (=D. 16,1,16,pr. )

ff. de pactis dotalibus l. Si inter virum .j. (=D. 23,4,24)

ff. de pactis dotalibus l. Si inter virum .ij. (=D. 23,4,31)

ff. de instructo l. Quaesitum § Papinianus .j. (=D. 33,7,12,23)

ff. de instructo l. Quaesitum \$ Papinianus .ij. (=D. 33,7,12,45)

ff. de auro argento l. Cum aurum § Idem Celsus libro .j. (=D. 34,2,19,3)

welches auch wohl geschah, oder man musste angeben, dass das dritte der fragmente, welche mit metum anfangen citirt sein solle:ff. quod. met. l. metum iij»

33 Hugo, Über die Art das Corpus iuris zu zitiren, cit., 217, confirma el método descrito y comprueba cómo degenera la cita en la que desaparece el inicio del fragmento hasta quedar reducida simplemente al número de la ley; desde l. metum .iij. D. quod. metus causa a l. Metum 9 D. Quod. Metus causa y finalmente 1.9 D. quod. metus causa ${ }^{33}$. Literalmente dice «die dritte Stelle im Titel quod metus causa 4,2, die mit dem Worte Metum anfang, ist von allen fragmenten dieses Titels das neunte. Man hatte Schon lange gesagt lex Metum 3 D. quod metus causa, nun sagte man lex Metum 9, und bald liess man das Anfangs Wort ganz weg und sesste blos lex 9».

34 Thibaut, Über die Arten das Corpus Iuris allegiren zu Romani, cit., 210. 
ff. de auro argento l. Cum aurum $\S$ Idem Celsus libro .ij. (=D. 34,2,19,6)

ff. de aqua \& aquae l. Si cui aqua pluvia § Item sciendum est .j. (=D. 39,3,1,13)

ff. de aqua \& aquae l. Si cui aqua pluvia \$Item sciendum est .ij. (=D. 39,3,1,17)

$f f$. de adquirendo rerum l. Si epistulam § Si qua insula .j. (=D. 41,1,65,1)

ff. de adquirendo rerum l. Si epistulam $\$$ Si qua insula .ij. (=D. 41,1,65,2)

ff. quod vi aut clam l. Interdictum quod vi .j. (=D. 43,24,17)

ff. quod vi aut clam l. Interdictum quod vi .ij. (=D. 43,24,19)

ff. de iure dotium l. Si debitor .j. (=D. 23,3,80)

ff. de iure dotium l. Si debitor .ij. (=D. 23,3,83)

ff. de heredibus l. Interdum haec \$ Sed si duos .j. (=D. 28,5,13,5)

ff. de heredibus l. Interdum haec $\$$ Sed si duos .ij. (=D. 28,5,13,6)

ff. de heredibus $l$. Si is qui .j. (=D. 28,5,56)

ff. de heredibus l. Si is qui .ij. (=D. 28,5,58)

ff.de legatis .j. l. Cetera igitur $\$$ Hoc senatus consultum .j. (=D. 30,41,6)

ff.de legatis .j. l. Cetera igitur $\S$ Hoc senatus consultum .ij. (=D. 30,41,8)

ff. de verborum obligationibus l. Si ita stipulatus .j. (=D. 45,1,12)

$f f$. de verborum obligationibus $l$. Si ita stipulatus .ij. (=D. 45,1,109)

ff. de dote praelegata l. Pater dotem a nuru $\$$ Sed si priusquam .j. (=D. 33,4,7,1)

ff. de dote praelegata l. Pater dotem a nuru § Sed si priusquam .ij. (=D. 33,4,7,3)

ff. de solutionibus l. Cum ex pluribus .j. (=D. 46,3,97)

ff. de solutionibus l. Cum ex pluribus .ij. (=D. 46,3,103)

ff. ad Legem Iuliam de Vi Publica l. Lege Iulia de .j. (=D. 48,6,1)

ff. ad Legem Iuliam de Vi Publica l. Lege Iulia de .ij. (=D. 48,6,7)

ff. de statuliberis l. Statuliberos condicioni § Si quis .j. (=D. 40,7,3,7)

ff. de statuliberis l. Statuliberos condicioni $\$$ Si quis .ij. (=D. 40,7,3,8)

El procedimiento descrito se aplica también en forma ordinal, de manera que cuando varios fragmentos de un mismo título o varios parágrafos de un mismo fragmento comienzan por las mismas palabras, y dan lugar a este método de cita, el número que los diferencia entre sí (.j. .ij. .iij. ...) puede ser sustituido por su ordinal en letras (primo/a, secundo/a, terzo/a, ...), implícita o explícitamente pero en todo caso éste es precedido por el artículo que proceda: «el», «la» «l.» («altoitaliano» ${ }^{35}$ para «il») o «loco». Es decir, «la»<lege> o «el» $<l o c o>$. Si recuperamos el ejemplo de D. 4,2,9, lo podríamos encontrar citado de las siguientes formas:

ff. quod. met. l. metum .iij. =

ff. quod. met. l. metum la .iij. =

ff. quod. met. l. metum loco. iijo $^{\circ} .=$

${ }^{35}$ Kantorowicz, Die Allegationen im spateren Mittelalter, cit., 17-18, proporciona una explicación espléndida de estas formas que, inicialmente, constituían una excepción. 
ff. quod. met. l. metum el terzo.

Como explicaré con detalle más adelante, también se aplican los números a los títulos pero sólo por su posición próxima, siguiente o anterior (.J: o .S:), a la posición actual. Por ejemplo, en la glosa de Accursio «c», \& a quibus, a D. 26,3,1, se cita de la siguiente forma un texto del título anterior:

$$
\text { ut.S.tit.j.l.ij.(= D. 26,2,2) }
$$

Menos cripticas resultan las citas contenidas en la glosa d, \& quo modo, a D. 26,3,1, todas ellas referidas también al título anterior:

ut supra tit.j.l.si quis ita (= D. 26,2,16 pr.)

ut supra tit.j.l.tutor incertus (= D. 26,2,20 pr.)

ut supra tit.j.l.tutor ita (= D. 26,2,23 pr.)

\section{BRAQUIGRAFÍA DE LOS ELEMENTOS QUE FORMAN LAS CITAS DE DIGESTO}

Hay tres partes básicas en la mayoría de las citas: el título de Digesto o rúbrica, la ley o fragmento y el responsum o parágrafo. A ellas se pueden sumar algunas veces el número de la ley y el número del parágrafo. Para citas anteriores al siglo XVI no resulta relevante el número del título ${ }^{36}$.

Las rúbricas de Digesto suelen ser identificadas sobre todo con la doble «ff.», pero a menudo también con la letra griega « $\pi$.»-a veces con y a veces sin una barra o vírgula que se superpone en la parte superior $^{37}$ - o, desde luego, con la letra mayúscula latina «D.». Sus fragmentos son introducidos generalmente con una «l.» (de lex) o con una «c.» (de caput) e individualizados por sus primeras palabras o incluso, en ocasiones, con el número del fragmento en cuestión; éste empieza a generalizarse a partir del Renacimiento. Los parágrafos van precedidos casi siempre del signo «§.» ${ }^{38}$.

${ }^{36}$ Müller, The recovery of Justinians Digest in the middle ages, en "Bulletin of Medieval Canon Law» 20, 1990, 3-30.

37 Modus allegandi textus utriusque juris, Augustae Vindelicorum, 1708, 2, confirma estas tres formas de refereirse a Digesto: «PANDECTAE, seu Digesta continent 50 libros, qui notati solent vel per graecum $\pi$. (aliquando cum, aliquando vero sine virgula superne exarata) vel per majusculam latinam $D$. vel per duplex $f f . »$

${ }^{38}$ Modus allegandi textus utriusque juris, cit., 2: «Textus ex his ita citantur, ut I. loco Lex secundum initialia ejus verba, vel etiam Numerus Legis referatur (qui tamen ultimus quandoque omittitur). Deinde, si Lex sit forte longior, additur § deinum Litterae Pandectarum indici adjicitur Titulus, sub queo ea Lex continetur». 
Modus allegandi textus utriusque juris es el título de un librito práctico, sin grandes pretensiones, publicado en 1708 en Augsburgo (entonces Augustae Vindelicorum), que resume los conocimientos básicos que existían sobre los modos de citar las obras de los corpora iuris civilis y canonici. Propone algunos ejemplos ${ }^{39}$-que reproduzco esquemáticamente- representativos de las variadas formas que pueden adoptar las citas de Digesto. No es una lista ni mucho menos cerrada, pues a ella se pueden sumar muchas otras modalidades (los tres primeros ejemplos corresponden a los glossatores juris canonici $\left.i^{40}\right)$ :

- Rúbrica y fragmento, pero sin separación entre ellas:

- ff de his, quae in fraud. cred. etsi pignus (= D. 42,8,18)

- Rúbrica, fragmento y parágrafo, pero también sin separación entre las dos primeras:

${ }^{39}$ Modus allegandi textus utriusque juris, Augustae Vindelicorum, 1708, 2-3: «... in hunc v.g. modum: $L$. Si quis vi. § differentia. $\pi$. de acquir. possess. id est: Lege, si quis vi, Paragrapho differentia, Pandectis de acquirenda possessione. - Eodem modo citantur Pandecta, seu Digesta sub nota $D$. vel ff. ut constat ex 2 seqq. exemplis: I.- $L$. naturalem autem, ff. de acquir. Dom. § Pavonum. Quae citatio sic legenda: Lege, quae incipit: Naturalem autem, et habetur in Digestis, sub Titulo: De acquirendo rerum Dominio, Paragrapho illius Tituli, que incipit: Pavonum. II. L. sed mihi, 3. §. si reddita D. commodati, id est: Lege sed mihi, quae est Tertia, Paragrapho: si reddita, Digestis (seu in Digestis) Titulo: Commodati. - Subinde additur Numerus suus etiam ipsi Paragrapho, uti in hoc exemplo: $L$. si Quadrupes 1. \$. ait Praetor 3 D. vel (quod idem est) ff. si quadrupes pauperiem fecisse dicatur. Cujus citationis iste est sensus: ita habetur in lege, quae incipita verbis: si quadrupes, et est prima inter ibi extantes, Paragrapho ejus tertio, incipiente a verbis: ait Praetor, extat autem in Digestis, sub Titulo qui inscribitur: si quadrupes pauperiem fecisse dicatur. - Subinde vicissim omisso Numero tam legis, quam Paragraphi, sic fit Pandectarum citatio: L. Servius. §. si aqua ff de riv. Cujus Citationis hic est sensus: Ita habetur in Titulo Digestorum de rivis. lege, quea incipit a verbo: Servius. §. si aqua. - Quadoque brevitatis causa solus legis et Paragrapimitur in hunc modum: L. 11. §. 4 ff ad L. Falcid. Hoc est: legis undecima Paragrapho quarto in Pandectis, sub Titulo: ad legem Facidiam. - Ejusdem brevitatis causa Glossator Juris Canonici, allegans Textus Pandectarum omittit initio Legum a se citatum praesigere litteram $L$ perinde ac in Jure Canonico initio capituli ex eo citati non semper praeponitur Littera $C$ patet in 3 seqq. exemplis: 1. ff de his, quae in fraud. cred. etsi pignus. 2.ff. de Offic. Praef. illicitas §. ne tenuis. 3.ff. de Precar. cum Precario. §. 1. Aliquando denique in citatione Digestorum primo loco ponitur illorum nota $D$. vel $f f$. vel $\pi$. Deinde Lex cum ejus Determinatione, vel faltem Numero; et, si Lex habet Paragraphos, ponitur etiam §. ejusque vel Determinatio, vel faltem Numerus, aut etiam utrumque in hunc modum: ff. de inoff. Test. L. Papinianus. 8. §. si conditioni: Hoc est: in Libro digestorum, vel Pandectarum, sub Titulo: de inofficioso testamento, Lege octava, quae incipit: Papinianus, et ejusdem Legis Paragrapho decimo, qui ita inchoatur: si conditioni».

${ }^{40}$ LANGE, Römisches Recht im Mittelalter: die Glossatoren, I, cit., 118-150 sobre las literaturformen de los glosadores. Véase también STOLLEIS \& WEIMAR, Ein biographisches Lexikon, Von der Antike bis zum 20. Jahrhundert, Munich, 1995, 18; ERLER \& KaufmanN, Handwörterbuch zur deutschen Rechtsgeschichte, Berlín, 1971, s.v. "Glossatoren», 1711; Hattenhauer \& Buschmann, Textbuch zur Privatrechtsgeschichte der Neuzeit mit Übersetzungen, Munich, 1967, 33-34; LuTz, Lexikon des Mittelalters, Munich, 1989, s.v. «Glossen», 1508. 
- ff. de Offic. Praes. illicitas §. ne tenuis (= D. 1,18,6,5)

- Rúbrica, fragmento y el número de parágrafo, pero nuevamente sin separación entre las dos primeras:

- ff. de Precar. cum Precario. §. 1 (= D. 43,26,21,141)

- Rúbrica, fragmento, número de fragmento y parágrafo:

- ff. de inoff. Test. l. Papinianus. 8. §. si conditioni (= D. 5,2,8,10)

- Fragmento, parágrafo y rúbrica:

- l. Si quis vi. $\S$ differentia. $\pi$. de acquir. possess. (= D. 41,2,17,1)

- Fragmento, parágrafo y rúbrica:

- l. Servius. §. si aqua ff de riv. (= D. 43,21,3,3)

- Fragmento, rúbrica y parágrafo:

- l. naturalem autem, ff. de acquir. Dom. § Pavonum (= D. 41,1,5,5)

- Fragmento, número de fragmento, parágrafo y rúbrica:

- l. sed mihi, 3. \$. si reddita D. commodati (= D. 13,6,3,1)

- Fragmento, número de fragmento, parágrafo, número de parágrafo y rúbrica:

- l. si Quadrupes 1. \$. ait Praetor 3 D. si quadrupes pauperiem fecisse dicatur (= D. 9,1,1,3)

- Número de fragmento, número de parágrafo y rúbrica:

- l. 11. \$. 4 ff ad l. Falcid. (= D. 35,2,11,4)

Añado cuatro ejemplos más propuestos por Kantorowicz ${ }^{42}$, en los que la cita viene introducida por las partículas «arg.»o «ut», muy características de los glosadores:

- Vt, rúbrica y fragmento:

- ut ff. ad l. iul. de adu. l. pe. (= D. 48, 5, 44)

- Vt, rúbrica y fragmento o fragmento y rúbrica:

- utff. de v. o. l. doli clausula o l. doli clausula ff de v. o. (= D. 45,1,119)

- Arg, rúbrica, fragmento numerado y parágrafo o parágrafo, fragmento numerado y referencia al título:

- arg. ff. de ince. ru. na. l.iij. § aliud o $\S$ aliud l.iij. eo. ti. (= D. 47,8,3,5)

- Y finalmente una cita un tanto especial, porque está compuesta por la rúbrica y el parágrafo pero falta completamente el fragmento que figura implícito; esto es, hay que deducirlo del initium del parágrafo:

- utff. ad l. iul. ambi. § qua lege (= D. 48,14,1,2)

${ }^{41}$ Obsérvese que D. 43,26,21,1 no existe en $F$. ni en la edición crítica.

${ }^{42}$ Kantorowicz, Die Allegationen im späteren Mittelalter, cit., 19. 
Todos estos ejemplos son correctos (con la salvedad de la nota efectuada a ff. de Precar. cum Precario. \$. 1) y se corresponden con citas reales de Digesto efectuadas entre los siglos XII al XVI. La principal enseñanza que contienen es el carácter absolutamente práctico de las citas, es decir, no importa en exceso el orden de sus partes ni su estructura ni que se ajuste a los cánones de citar que son predominantes en cada época; lo relevante es que la cita, de una forma o de otra, permita identificar la fuente a la que se refiere.

Ahora bien, no siempre las citas son tan evidentes o claras como las de los ejemplos que acabo de transcribir. Para la mejor interpretación de las citas de Digesto resulta conveniente contar con la información adicional que facilito a continuación.

\section{III.1. «ff.» como aféresis de «D.» o de « $\pi$.»}

Aunque hay otras formas más técnicas en determinados contextos -como ..ं., .j., .J: o .S.- a las que luego me referiré, Digesto, con carácter general, es declarado en las citas por medio de tres signos equivalentes ya mencionados que se usan indistintamente: «D.», «ff.» o « $\pi$.», así como por derivados de ellos como «dg.», "dig.», etc. Este hecho se comprueba con facilidad, en primer lugar, en las fuentes, pero también en los comentarios explicativos, tales como

Aliquando denique in citatione Digestorum primo loco ponitur illorum nota D. vel ff. vel $\pi$. $^{43}$

o también

PANDECTAE, seu Digesta ... qui notati solent vel per graecum $\pi$. vel per majusculam latinam $D$. vel per duplex ff.

De los tres grafemas, no ofrecen dificultad ninguna «D.» ni

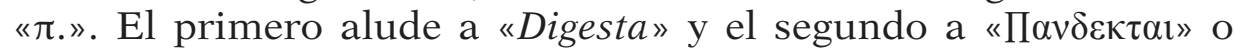
« $\pi \alpha \nu \delta \varepsilon \kappa \tau \tilde{\omega} v »$ o «Pandectae». Sin embargo durante mucho tiempo no ha estado claro cuál es el origen y el significado inicial de «ff.». Al principio se sostiene la idea de que es una degeneración de « $\pi$.»por pérdida de una vírgula de abreviación que suele aparecer en su parte superio ${ }^{44}$. También se ha sugerido que podría significar Farrago fa-

${ }^{43}$ Modus allegandi textus utriusque juris, Augustae Vindelicorum, 1708, 2.

${ }^{44}$ Mackeldey, Compendium of modern civil law, New York, 1845, 54, nt. d: "D. signifies Digesta, as do a1so the letters $f f$. These latter it is supposed by our author -and indeed by the majority of jurists- originated from the letter $D$. by the addition of a stroke of abbreviation. But a more probable supposition is, that it arose from a 
rraginum $^{45}$ o factae fuerint o incluso que proceda de «ll.» (libri 50 $)^{46}$. La lista completa de teorías la ofrece Cramer ${ }^{47}$. La tesis más extraña, comentada por Savigny ${ }^{48}$, atribuye el signo a las dos efes por las que comienzan los nombres de los emperadores del Sacro Imperio Romano Federico I y II, en homenaje a la gran devoción que muestran por el derecho romano. Finalmente se ha impuesto la idea de que «f.» deriva de la letra «D».

Lo que es seguro es que $f f$ es la abreviatura de una abreviatura, por ello es una aféresis bien de « $\pi$.» bien, con más probabilidad, de «D».

Del origen del significado de «ff.», a pesar de que se trata de una cuestión con interés relativo, se ocupan practicamente la totalidad de los autores que estudian las citas de Digesto. Una de las primeras referencias doctrinales la ofrece Giuseppe Averani -maestro de Brenkmann- en su Istoria delle Pandette Fiorentine, plasmada en un manuscrito del siglo XVII, sin data exacta, que se encuentra en la $B i$ blioteca medicea Laurenziana de Florencia. Pertenece a la colección «Ashburnham» con el n. ${ }^{\circ} 1332$. En los fols. 4v-5v, se recoge el liber I $\S 13$ relativo a la forma de citar los textos de Digesto. Conocemos su contenido gracias a la reciente transcripción de Baldi ${ }^{49}$ de quien la tomo y, por su interés, reproduzco:

«§ 13. La maniera poi di citare le Pandette si ristringe a indicare il Capitolo o Legge come voglia chiamarsi, e insieme il Titolo, sotto del quale tal Legge è posta; così per ragion d'esempio volendo citare quel luogo di Paolo riferito nelle Pandette, ove si dice che -Invito beneficium non datur - si direbbe L. 69 nel titolo de diversis regulis juris; ma per non stare a nominare ogni volta il titolo, ciò si suppone, e si nota semplicemente la prima lettera con la quale si scrive Pandette o Digesti e per ordinario la medesima cosa indicano quelle due $f f$ che comunemente si usano. Fanno al solito

careless mode of writing the Greek $\pi$; and this is confirmed by the fact that the Latin $P$ or the Greek $\pi$, is sometimes used an abbreviation of Pandectae or $\prod \alpha v \delta \varepsilon \kappa \tau \alpha$.

45 JorTin, Remarks on ecclesiastical history, Londres, 1767, 188.

${ }^{46}$ SPANgEnBerg, Einleitung in das römisch-justinianeische Rechtsbuch: Oder Corpus juris civilis Romani, Hannover, 1817, 166 nt. 13, al comentar el trabajo de Hugo sobre ff menciona todas estas posiblidades: «nach der meinung anderer soll es bald

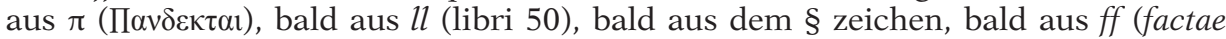
fuerint oder Farrago farraginum) entstanden sein».

${ }^{47}$ Cramer, Programma de sigla Digestorum ff, Kiliae, 1796, 4.

${ }^{48}$ SAvignY, Geschichte des römischen Rechts im Mittelalter, vol. 3, Heidelberg, $1834,444$.

${ }^{49}$ BALDI, Il Codex Florentinus del Digesto e il Fondo Pandette della Biblioteca Laurenziana (con un'appendice dei documenti inediti), en «Segno e Testo» 8, 2010, 160-161. 
l'inutil questione gl'interpreti qual origine abbia avuto un tal modo di esprimere i libri delle Pandette. L'opinione migliore è quella, che citandosi le Pandette dai greci, si notava semplicemente la prima lettera $P$. susseguentemente dovendosi fare le medesime citazioni in occidente, e quando la lingua greca più non si usava, si ritenne la stessa iniziale, che cominciando a corrompersi facilmente fu creduto che non si dovesse scrivere $P$ ma più tosto $f f$ che poi è a noi rimasto, tramandatoci da tempi barbari; cosicchè ci serviamo di questo segno ff per indicare la collezione delle Pandette. ${ }^{50}$

Esta noción de vincular el origen de ff. a una letra griega o, al menos, a la palabra que ésta representa se mantiene hasta que es desautorizada por Hugo. El propio Hugo, al comenzar su exposición, reconoce que sobre el origen del símbolo ff la opinión mejor y más viable, entre las que pueden leerse, es que procede de una $\pi$ o un $p p$, es decir, ff sustituye a la palabra Pandectae y no a Digesta ${ }^{51}$. Sin embargo, su trabajo llega a la conclusión contraria. Parte de los estudios de Dü Tillet y de los análisis paleográficos sobre manuscritos de la alta edad media de Cramer, en su Programma de sigla Digestorum ff $^{52}$, y concluye que en estos manuscritos ff. es seguido de los sufijos o terminaciones propias de Digestum, no de Pandectae ${ }^{53}$. Es decir, se puede leer en aquellos manuscritos ff.tum o ff.torum (Digestum / Digestorum) pero nunca ff.tae o ff.tarum (Pandectae / Pandectarum) ${ }^{54}$. A este argumen-

${ }^{50}$ Averani, Istoria delle Pandette Fiorentine, ms. «Ashb.»1332, fols. 4v-5v,

${ }^{51}$ Hugo, Wahrer Ursprung des ff., en "Civilistisches Magazin», 3, § VI, Berlin 1812, 110-112, estudia el verdadero origen del símbolo «ff.» En 111 dice «Unter den bisherigen Meinungen über den Ursprung des ff gehen die besten und gangbarsten z. B. die, das es ein $\pi$ oder ein $p p$. sei, davon aus, das "ff." müsse Pandectae und nicht Digesta gelesen werden».

${ }^{52}$ CRAMer, Programma de sigla Digestorum ff, cit., 5 ss. con un estudio paelográfico de manuscritos de la alta edad media. VANo, Der Gaius der Historischen Rechtsschule: Eine Geschichte der Wissenschaft vom römischen Recht, Frankfurt am Main, 2008, le dedica a las investigaciones de Cramer el apartado $5 \mathrm{y}$, en concreto, sus observaciones al Programma de sigla Digestorum «ff» se pueden ver en 67 y en nt 75.

${ }^{53}$ HöPFnER, Theoretisch praktischer Commentar über die Heineccischen Institutionen, Frankfurt am Main, 1833, 13 nt. 15, contiene un resumen bastante completo de las teorías formuladas sobre ff, desde Cramer a Dü Tillet, y finaliza con Hugo, del que destaca que la explicación del carácter del signo se observa, en particular, en lo que ocurre en los antiguos manuscritos con las abreviaturas ffti y fftorum: «Diese Erklärung des erwähnten Zeichens wird auch besonders durch die in den alten Schriften vorkommenden Abkurzungen: ffti und fftorum».

${ }^{54}$ Hugo, Wahrer Ursprung des ff., cit., 112: «Allein theils war sonst der name Digesta bei den lateinern weit gewöhnlicher, wie man schon aus Eintheilung Digestum vetus, infortiatum und novum sieht; theils widerlegt sich auch diese Meinung durch die vielen handschriften und alten Drucke, die hinter dem ff die Endsilben von Digestum nähinlich ein tum oder torum haben, nie aber ein tae oder tarum, wie den dem Worte Pandectae sein müsste». 
to, ciertamente convincente, añade algunos datos adicionales entre los que merece la pena destacar dos: a) los Digesta de Juliano o los de Escaevola nunca fueron llamados Pandectas, pero, como observó Dü Tillet, son declarados también por la sigla $f f^{55}$; y b) la indudable preferencia de los bononienses por el término latino antes que por el griego, como lo demuestran, por ejemplo, los apelativos de Digestum vetus o novum. Por todo lo cual concluye que «ff no es otra cosa que una «D.» la letra inicial de Digesto» (ff ... und diess ist denn nichts anders als ein „D. «... der anfangsbuchstabe von Digestum $)^{56}$.

La doctrina acepta la explicación de Hugo de identificar «ff.» y «D.», que es apoyada inmediatamente sin reservas por Spangenberg $^{57}$, Erxleben ${ }^{58}$, Höpfner ${ }^{59}$, Mackeldey ${ }^{60}$ y muchos más después, entre los que se encuentra el propio Kantorowicz ${ }^{61}$. Este último añade un dato que facilita la conversión de «D.» en «ff.» y es que cree que deriva del conjunto formado por una «Đ.» con un trazo o carrera que la atraviesa (aus einem durchgestrichenen «D.» entstanden). Imagino que quiere indicar algo parecido a lo que sucede con la $R$ de rúbrica en $F$., que figura atravesada por una carrera. En mi opinión esta ultima sugerencia es razonable y termina de explicar el proceso de conversión, si bien me parece que es más propio de una cita el emplear un trazo de abreviación, por tanto superpuesto a la letra: «D.» Lange $^{62}$ es el último en unirse a esta teoría.

${ }^{55}$ Hugo, Wahrer Ursprung des ff., cit., 111: "Dü Tillet schrieb auch einer handschrift der Pandecten, wo den Stellen aus Julian's oder Scaevola's Digesten, die doch nie Pandecten geheissen haben, eben diese abkürzung sich findet, aus welcher das ff entstanden ist».

${ }^{56}$ Hugo, Wahrer Ursprung des ff., cit., 112.

${ }^{57}$ SPANGENBERG, Einleitung in das römisch-justinianeische Rechtsbuch, cit., 166: "Ausserdem ist noch zu bemerken, dass die Pandekten, gewöhnlich durch das Zeichen $f f$, welches ein geschlungenes $D$., d.h. Digestum, ursprünglich war, nie aber $P$ oder Pandectae gelesen werden darf, bezeichnet, und demgemäss z.B. L.1 ff de just. et jure in altern Werten citirt wird».

58 ERXLEBEN, Lehrbuch des römischen Rechts: Einleitung in das römische Privatrecht, Volumen 1, Göttingen, 1854, 361 nt. 189, reproduce la tesis de Hugo.

${ }^{59}$ HÖPFNER, Theoretisch praktischer Commentar über die Heineccischen Institutionen, cit., 13.

${ }^{60}$ Mackeldey, Compendium of modern civil law, cit., 54.

${ }^{61}$ Kantorowicz, Die Allegationen im späteren Mittelalter, cit., 19: «Digesta , d. h. die Pandekten (a. 533), allegiert mit ff. (aus einem durchgestrichenen D. entstanden; vgl. die Redensart „etwas aus dem ff. Kennen“, d. h. nicht aus den Institutionen, sondern aus den Digesten, also gründlich kennen)».

${ }^{62}$ LANGE, Römisches Recht im Mittelalter: die Glossatoren, I, cit., 63 concluye que «die Sigle für die Digesten war „ff.", entstanden mutmasslich aus einem durchs trichenen D». 


\section{III.2. Referencia a Digesto como obra}

En todo caso, ya se utilice «D.» o «ff.»o « $\pi . »$, éstos preceden siempre a una rúbrica de Digesto y nunca a los libros ${ }^{63}$.

Ahora bien, la sigla puede ser omitida -y de hecho lo es- cuando la referencia a Digesto resulta obvia ${ }^{64}$. En la posición de la sigla se pueden colocar, entre otros signos, una.$\dot{s}$. o una.$j$. que indican, respectivamente, supra o infra. Éstos pueden usarse en conjunto con otras abreviaturas, tales como:

\section{.̇. tit. .j. (= supra titulus primus $)^{65}$}

Otros manuscritos dibujan estos grafemas de forma algo diferente, en lugar de un ${ }^{\mathrm{O}}{ }^{\mathrm{i}}$ » o una " $^{\mathrm{a}} »$ superpuestas hay una especie de diéresis: .S: = supra o una .J: = infra ${ }^{66}$; por ejemplo:

.J.tit. j. (= infra titulus primus $)^{67}$

También se utilizaron las combinaciones de grafemas y abreviaturas .S:l. proxima (o .s..q.prox.) y .J:l. proxima (o .ja.q.prox. $)^{68}$ para referirse, respectivamente, a un fragmento anterior o siguiente ${ }^{69}$.

Un ejemplo del empleo de esta técnica en la forma de citar Digesto entre los comentaristas puede verse en los comentaria de Jacopus Butrigarius (siglo XIV) ${ }^{70}$ :

ut l. feminae .J: de reg.iur (= D. 50,17,2).

63 Schrage, Utrumque Ius. Eine Einführung in das Studium der Quellen des mittelalterlichen gelehrten Rechts, Berlín 1992, 31-33.

${ }^{64}$ Esta posibilidad no solo se da en Digesto sino, en general, en las obras que aún no siendo sistemáticas se organizan de acuerdo a un orden legal y cuando los textos que se refieren a la misma obra deban ser citados con suficiente claridad, tal como acertadamente indica KANTOROWICZ, Die Allegationen im späteren Mittelalter, cit., 18.

65 ThiBaut, Über die Arten das Corpus Iuris allegiren zu Romani, cit., 220, interpretación que no comparte KanTOROWICZ, Die Allegationen im späteren Mittelalter, cit., 18 que afirma «... oder auch ..ं. tit. $j$. gesetzt (was also nicht etwa den ersten Titel des kommentierten Rechtsbuches bedeutet)».

66 Thibaut, Über die Arten das Corpus Iuris allegiren zu Romani, cit., 220.

67 Thibaut, Über die Arten das Corpus Iuris allegiren zu Romani, cit., 221.

68 Kantorowicz, Die Allegationen im späteren Mittelalter, cit., 18.

69 ThiBaut, Über die Arten das Corpus Iuris allegiren zu Romani, cit., 221 define la primera como «eine gleich vorhergehende» y la segunda «eine gleich folgende».

70 Jacobus Butrigarius, Commentaria Eruditissima atque pariter accutissima in quamplurimos iuris communis titulos, Romae apud: Typis Lepidi Fatij, 1617, 31. LANGE \& Kriechbaum, Römisches Recht im Mittelalter:II. Die Kommentatoren, cit., 630, estudian esta obra de J. Butrigario a la que atribuyen, por error, un título diferente. 
Pero el procedimiento .J: / .S. es anterior y está absolutamente extendido entre los glosadores. Un ejemplo cualquiera de .J: en sustitución de ff., se puede ver en la glosa «d» a D.5,3,20,7 en Digestum Vetus:

$$
\text { ut .J.e.l\$ait Senatus (= D. 5,3,20,7) }
$$

Para interpretar adecuadamente este último ejemplo, debe tenerse en cuenta que cuando el texto se refiere a una parte ya comentada antes, o que lo es ahora, se coloca detrás de la .s.., .j., .J: o.S. un eodem o un eadem en femenino, según proceda, o sus abreviaturas: e. o eo. o ea. o e.l. o eo.ti., ...En consecuencia, por lo que se refiere a aquel ejemplo, .J:e.l significa infra eodem lex, lo que en este caso concreto incluye también al eodem titulo de Digesto. Otras combinaciones frecuentes:

.S.e.l. = supra eodem lex

.S.ea.l.\$. = supra eadem lege $\$$, etc

Obsérvese la combinación de estos dos textos que he extraído de la glosa «a», Non fieri, de Accursio a D.12,1,18 en Digestum Vetus:

ut infra, eo.l.ij.§.si. (= D. 18,1,2,1= l. Inter patrem $\S$ Sine pretio ff. de contrahenda emptione)

ut dixi infra, de contrahen.emp.l.in venditionibus (= D. 18,1,9,pr. =l. In venditionibus $\pi$. de contrahenda emptione)

y otro procedente de la glosa «c», gesserit, a D.3,5,3:

ut .J.ea.l. § haec verba;

obsérvese que la cita es defectuosa por incompleta ya que con ella se puede señalar a dos parágrafos -D. 3,5,3,1 o 3,5,3,6- que comparten ese initium, por lo que lo correcto hubiera sido:

ut .J.ea.l. § haec verba si quis = ut .J.ea.l. \$ haec verba .j. (= D. 3,5,3,1) ut .J.ea.l. § haec verba sive $=$ Vt .J.ea.l. $\$$ haec verba .ij. (= D. 3,5,3,6)

Por último, rara vez aparece en las citas la división medieval y tripartita de Digesto ${ }^{71}$. No obstante las ocasiones en las que sucede, la sílaba ff. figura vinculada exclusivamente a los Digesta vetus \& novum (ff. vetus, ff. novum), nunca al Infortiatum por razones obvias ${ }^{72}$.

${ }^{71}$ Digestum vetus: libros 1-24,2; Infortiatum: libros 24,3-38 (el último tramo, de D. 35,2,82 v. tres partes en adelante, fue llamado Tres Partes después de su initium); y Digestum novum: libros 39-50.

${ }^{72}$ KutTner, The revival of jurisprudence, en "Renaissance and renewal in the twelfth century», Oxford, 1982, 299-323. 


\section{III.3. Declaración de títulos y rúbricas}

Digesto está dividido en libros y éstos en títulos. Los títulos adoptan caracteres destacados en todos los mmss. y, por tanto, también en $V$. y en $F$. En este último están en letras mayúsculas rojas flanqueados por la abreviatura «R» de rúbrica, y sin numerar ${ }^{73}$.

En las citas, el título se expresa generalmente con el grafema $T$. o la abreviatura Tit., y su rúbrica por Rubr. (= Rubrum) Tit. ${ }^{74}$. Los títulos enteros suelen ser declarados por los glosadores con la combinación t.t. y, más tarde, con tot.tit. (toto titulo). También en estos casos, cuando lo que se desea citar es un título completo, la rúbrica suele ser acompañada de la expresión per totum ${ }^{75}$.

Si se ha mencionado ya un título y debe citarse nuevamente, o también cuando lo que debe citarse es el título de otra obra que tiene la misma rúbrica u otra parecida, por lo general ésta no se repite y es sustituida por la sigla de la obra (v.gr.ff., C., I., ...) seguida por eo. ${ }^{76}$ o e. o eod. ${ }^{77}$ (= eodem), así como eod.ti. o eo.ti. o e.ti. (= eodem titulo). Numerosos ejemplos se pueden ver en Guido Panciroli ${ }^{78}$ (siglo XVI) que bajo el epígrafe «Aliquot jura in Codice, \& Pandectis sub diversis titulis repetita, aut divisa» recoge las repeticiones que se dan entre Digesto y el Código de Justiniano (Iura Pandectarum in Codice repetita) lo que casi siempre sucede entre textos bajo rúbricas muy similares:

l. iuris gentium $\S$ ait praetor.ff.de pact. insertal.pen. C.eod. (= D. 2,14,7,7)

l. Nessenius.34.ff.de neg.gest. citat l.alimenta.C.eod (= D. 3,5,33 = Vulg. 34)

l. is qui.44.ff.eod. repetita in l.i.C.eod.tit. $(=$ D. 3,5,43 = Vulg. 44)

${ }^{73}$ Mommsen, Praefatio, cit., X: «Rubricae: Singuli libri constant titulis, qui in codice archetypo distinguebantur sine dubio, ut distinguuntur in Florentino, et litteris maioribus et rubro colore et nota rubricam significante "R" eaque bis posita et ante tituli uerba et post ea. Numeros titulis ab ipsis compilatoribus nullos adscriptos fuisse cum inde colligitur, quod in uolumine Florentino paucis locis exceptis correctores demum eos addiderunt, tum quod ubiuis scribuntur notis, non litteris. nam cum notarum etiam numeralium interdictio in primordiis digestorum expressa ad uniuersa digesta perueniat, si rubricae in archetypo exemplari numeratae fuissent, numeri hi ante singulos titulos litteris perscripti non ita euanuissent, ut nullum usquam eorum uestigium remaneret. mature tamen hosce numeros adiectos esse et antiquissimi codicis habitus declarat et allegationum tam Graecorum quam Latinorum auctorum ratio: nec nos eos recipere dubitauimus».

${ }^{74}$ ThiBaut, Über die Arten das Corpus Iuris allegiren zu Romani, 224-225.

${ }^{75}$ Kantorowicz, Die Allegationen im späteren Mittelalter, cit., 17.

${ }^{76}$ Kantorowicz, Die Allegationen im späteren Mittelalter, cit., 18.

77 Thibaut, Über die Arten das Corpus Iuris allegiren zu Romani, cit., 219.

${ }^{78}$ GuIdo PANCIROLI, Thesaurus variarum lectionum vtriusque iuris in tres libros distinctus, Venetiis, apud: Ioannem Guirelium, 1610, 113. 
l. pignoris.17.de pignor. est l.pignoris.18.C.eod (= D. 20,1,17)

Se observa en estos ejemplos la utilización de ff.eod. y C.eod. o C.eod.tit. para referirse, respectivamente, al título previamente mencionado de Digesto (D. 3,5) o a rúbricas del Codex que tratan el mismo tema. Por cierto, en los ejemplos expuestos de Panciroli, la mención de los números junto al initium dejan al descubierto las diferencias de numeración entre las Vulgatas y $F$ (f. $64 r$.) como consecuencia de haberse eliminado en la edición crítica la inscripción de D. 3,5,6 que, en esta última, pasa a ser D. 3,5,5,2.

Por otro lado, como es sabido, los libros 30, 31, y 32 no se dividieron en títulos, por lo que se citan como tales, es decir, por la rúbrica común de legatis et fideicommissis, (generalmente abreviada de legatis o simplemente su apócope de le.) a la que se le añade el número distintivo: .j., .ij. o .iij. ${ }^{79}$. Por ejemplo ${ }^{80}$ :

l. Si tutor pupillam D. de legatis .j. (= D. 30,128)

l. In arbitrium $\S$ Sed cum ita ff. de legatis .ij. (= D. 31,1,1)

ff. de le .iij. l. Fideicommissa quocumque § Sic fideicommissum (= D. $32,11,5)$

Esta manera de citar los tres libros se mantuvo mucho tiempo y llega hasta Savigny (que se caracteriza además por omitir la letra $D$.) que suele añadir al número del libro la abreviatura «un.» para indicar que tiene un título único. Por ejemplo ${ }^{81}$ :

\section{1. $49 \S 4$ et de legatis fideicommissis (31 un.). (= D. 31,49,4)}

${ }^{79}$ ThiBaut, Über die Arten das Corpus Iuris allegiren zu Romani, cit., 211.

${ }^{80}$ MaCKeldeY, Compendium of modern civil law, cit. 54-55, propone otros ejemplos de citas de estos tres libros: «As to the 30th, 31st, and 32d books of the Pandects, it deserves to be noticed that they consist only of fragments, and are not divided into titles, but form a treatise of their own de legatis et fideicommisis which is divided into three parts; consequently, Dig. lib. 30. = lib. 1. de legatis; Dig. lib. 31. =lib. 2. de legatis; Dig. lib. 32. = lib. 3. de legatis. The manner of citing them is therefore this: $f r$. 108. § 3. D. de legalis I. or D. 30; fr. 76. § 1. D. de legatia II. or D. 31; fr. 36. D. de legatis III. or D. 32 ».

${ }^{81}$ Robled, Introduzione allo studio del Diritto privato romano, cit. 370: «I Riti 3032 dei Digesta, poichè non hanno che un solo titolo, con la stessa rubrica in tutti e tre: De legatis et fideiconnissis, le citazioni non hanno mai più di tre numeri; manca, infatti il numero o cifra del titolo. Cosi: D. 30, 8,1 i= Digesta, libr. 30, lex (o fr.) 8, § 1. Oppure (precedentemente): $1.8 \S$ I D. de legatis et fideicommissis, $30=$ lex 8 paragr. 1. Digesta, parole della rubrica, libr. 30. Oppure: $1.8 \S 1$ de legatis et fideicommissis (30 un.). Questo modo di citare, come si può subito avvertire, è del Savigny, poiché omette la sigla D. Quell'un significa il titolo único». 
Por lo demás, con un criterio que recuerda a las abreviaturas de la antigüedad (como las notae iuris ${ }^{82}$, las notae publicae del siglo I de Valerio Probo o los notarum laterculi $i^{83}$ ), las rúbricas no solo son por regla general acortadas sino, en ocasiones, reducidas a simples siglas. Esto último sucede solo con los títulos más conocidos. El resto de las rúbricas, prácticamente sin excepción, son abreviadas mediante el proceso reductor más simple: el de suspensión, es decir, el de eliminación de las letras finales de sus palabras. Por ejemplo, De tutelae et rationibus distrahendis et utili curationis causa actione (D. 27,3) se expresa de tutel. et rat. distr., y la rúbrica De adquirenda vel omittenda hereditate (D. 29,2) se reduce a de adquir. her., o también -y esto puede causar mayores problemas de identificación porque se altera el orden alfabético- el título De adquirenda vel amittenda possessione (D. 41,2) se limita a su palabra más importante a pesar de que se encuentra al final: de possessione ${ }^{84}$.

Rara vez se somete a las rúbricas a abreviaciones por sincopa o contracción, en las que se suprima letras por el centro de las palabras. Una excepción a esta regla aparece en voces tales como Senatus Consultum que con frecuencia se abrevia en SCt (v.gr. ad SCt Vell. en lugar de ad Senatus Consultum Velleianum = D. 16,1)

Cuanto más conocidas son las rúbricas más drásticas resultan sus abreviaturas, hasta quedar reducidas muchas veces a simples letras iniciales. No hay garantías de que éstas siempre representen las palabras por su orden tal como figuran en la rúbrica (v.gr.: de $R$. D. siglas de rerum divisione cuando el título de la rúbrica es De divisione rerum et qualitate), pues a menudo estas litterae singulares se refieren a las palabras más importantes, con independencia de su posición, y prescinden del resto (v.gr.: de O.J. significa origine iuris pero la rúbrica es mucho más extensa: De origine iuris et omnium magistratuum et successione prudentium).

Son ejemplos muy conocidos de estas mutilaciones las siguientes rúbricas ${ }^{85}$ :

de A. R. D. = adquirendo rerum dominio (= D. 41,1)

${ }^{82}$ Esta es la opinión de KANTOROWICZ, Die Allegationen im späteren Mittelalter, cit., 18: «Der Text der Initien der Leges und Paragraphen weicht infolge veränderter Textgestaltung, Einteilung und Bezifferung von dem der heutigen Ausgaben nicht selten ab, ebenso der Text der Titelrubriken, die ausserdem beschränkt wurden auf die notwendigsten Worte, und diese wurden ihrerseits auf stärkste abgekürzt. Insoweit dürfte ein geschichtlicher Zusammenhang mit den notae iuris des Altertums vorliegen».

${ }^{83}$ KeIl \& Mommsen, Notarum Laterculi, en «Gramatici Latini», Leipzig, 1864 (reedición en Cambridge 2009, vol. 4), 271.

${ }^{84}$ ThiBaut, Über die Arten das Corpus Iuris allegiren zu Romani, cit., 226-227.

${ }^{85}$ Algunos ejemplos más pueden verse en Pou, Historia externa del derecho ro- 
de A.E.V. = actionibus empti venditi (= D. 19,1)

de B. P. c. t. = bonorum possessione contra tabulas $(=\mathrm{D} .37,4)$

de B. P. s. t. = bonorum possessione secundum tabulas (= D. 37,11)

de donat. int. $V \cdot V=$ virum et uxorem $(=$ D. 24,1$)$

de L.L. = legibus (= D. 1,3)

de O.A [o también de A.O, o O. et A.] = obligationibus et actionibus (= D. 44,7)

de O.J. = origine iuris $(=\mathrm{D} .1,2)$

de $R . C .=$ rebus creditis $(=\mathrm{D} .12,1)$

de $R$. D. = rerum divisione $(=\mathrm{D} .1,8)$

de $R . I .=$ regulis iuris $(=\mathrm{D} .50,17)$

de $R . N$. = ritu nuptiarum (= D. 23,2)

de $R . V$. = rei vindicatione $(=\mathrm{D} .6,1)$

de S.P.R = servitutibus praediorum rusticorum $(=\mathrm{D} .8,3)$

de $V . O=$ verborum obligationibus (= D. 45,1$)$

de V.S. = verborum significatione $(=\mathrm{D} .50,16)$

Muchas veces se producen alteraciones en las rúbricas y en las formas de citarlas, con modificación incluso del orden o del caso latino en el que figuran. La razón originaria de estos cambios se encuentra generalmente en las distintas variantes que un título puede tener en las obras del Corpus iuris o en sus manuscritos ${ }^{86}$. He cotejado el elenco de Thibaut ${ }^{87}$, que recojo a continuación, con algunas Vulgatas y he encontrado pequeñas diferencias con las alteraciones que él menciona: por ejemplo, la edición lionesa del infortiatum de 1569 en la que en lugar de la rúbrica correcta (D. 25,4): De inspiciendo ventre custodiendoque partu figura de ventre inspiciendo de partu custodiendu (y no solo de ventre inspiciendo); etc. También con las Digesti novi rubricae de la edición veneciana de 1606 en la que en lugar de De lege Pompeia (D. 48,9) figura ad legem Pompeiam; o en lugar de De duobus reis constituendis (D. 45,2) figura de duobus reis constituendi stipulandi et promittendi; etc... Una relación por orden alfabético:

- De aqua et aquae pluviae arcendae (= D. 39,3) -> de aqua pluvia arcenda;

- De dotis collatione (= D. 37,7) -> de collat. dotis

- De duobus reis constituendis (= D. 45,2) -> de duobus reis constituendi stipulandi et promittendi

mano, Barcelona, 1884, 406 y THIBAUT, Über die Arten das Corpus Iuris allegiren zu Romani, cit., 265.

86 Radding \& Ciaralli, The Corpus Iuris Civilis in the Middle Ages: Manuscripts And Transmission from the Sixth Century to the Juristic Revival (Volumen 147 de "Brill's Studies in Intellectual History») Leiden-Boston 2007, dedica a Digesto 169-200.

87 ThiBaut, Über die Arten das Corpus Iuris allegiren zu Romani, cit., 227-228. 
- De inspiciendo ventre custodiendoque partu (= D. 25,4) -> de ventre inspiciendo

- De lege Pompeia de parricidiis (= D. 48,9) -> ad legem Pompeiam

- De libertis universitatium (= D. 38,3) -> de libertis municipum et aliarum universitatum

- De testamento militis (= D. 29,1) -> de militari testamento

- De tutelae et rationibus distrahendis et utili curationis causa actio$n e(=$ D. 27,3$)->$ de tutelis et rat. distr.

- De veteranis (= D. 49,18$)->$ de priviliegiis ${ }^{88}$ veteranorum

- Qui testamenta facere possunt et quemadmodum testamenta fiant (= D. 28,1)-> qui testam. facere possunt

- Quod legatorum (= D. 43,3) -> quorum legatorum

- Testamenta quemadmodum aperiuntur inspiciantur et describantur (= D. 29,3) -> testamenta quem aper.

Por último, en las ediciones de la Vulgata del siglo XV y XVI he encontrado frecuentemente signos generales de abreviación usados para suprimir, sustituir o unificar dos o más letras de una rúbrica en una especie de sinéresis grafica. Esto sucede sobre todo en los Digesta rubricae que aparecen en los introitos de cada una de las tres partes de la antigua división medieval. Así, se lee constantemente la

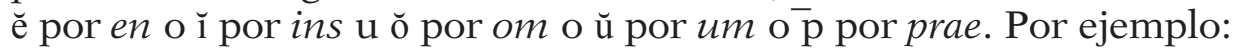
de vĕtre inspiciědo de partu custodiědu ${ }^{89}$.

\section{III.4. Initium de leyes o fragmentos}

Los títulos de Digesto se subdividen en pasajes de obras jurisprudenciales de diferentes juristas. En el siglo VI, tanto los compiladores como los antecessores, los denominaban «digesta», en la edad media «leges», en el renacimiento «leges» o "capita», y hoy fragmentos. Estos nombres determinan la forma de ser citados y las dos letras que los identifican en las citas: $l$. = lex y $c$. = caput.

La edición crítica de Digesto cuenta con 9139 fragmentos. Sin embargo esta cifra no coincide con el número de fragmentos que tiene $F$ ni con la del resto de mmss. A su vez éstos tampoco suelen concordar entre sí. La razón de esas diferencias es múltiple: homoioteleuton, caída de inscripciones, omisión de fragmentos, uniones indebidas, segregaciones erróneas, e incluso adiciones de textos adventicios como es el caso conocido de D. 22,3,30 y 22,3,31 que, a pesar

${ }^{88}$ En Digesti novi rubricae; libri undecimi: «privilegio».

${ }^{89}$ En Infortiati rubricae; liber primus. 
de figurar en $F$, son excluidos por Mommsen tanto por ser tachados por $F 2$ como por no figurar en $B^{90}$.

Ahora bien, con probabilidad la causa que más favorece esas diferencias es que los fragmentos no figuran numerados en $F$ ni, por tanto, en su arquetipo ${ }^{91}$. Este hecho impide a los copistas de los mmss. constatar las desviaciones producidas en el proceso de copia. Y hay una segunda consecuencia: la necesidad de citar los fragmentos por sus initia ante la inexistencia de un sistema de correspondencias numéricas fiable.

Antes o después de la rúbrica, las citas incluyen las primeras palabras del fragmento en tanto sean necesarias para su diferenciación con los otros. Por ejemplo:

ff. de V.O. l. stipulationes commodissimum (=D. 45,1,53)

Como he dicho ya, el número de palabras del initium oscila generalmente entre una y $\operatorname{cinco}^{92}$, aunque en caso de coincidencia con otro fragmento resulta ortodoxo el acotar el initium mediante su numeración dentro de la sección en la que se encuentre. A este efecto la única o última «i» es reemplazada por una « $j »$ y la cifra se encierra entre puntos (.j., .ij., .iij., ...). Por ejemplo:

ff. de V.O. l. stipulationes .j. (=D. 45,1,53)

ff. de V.O. l. stipulationes .ij. (=D. 45,1,72)

$\mathrm{O}$

ff. de testamentaria l. tutor.j. (=D. 26,2,8)

ff. de testamentaria l. tutor.ij. (=D. 26,2,20)

ff. de testamentaria l. tutor .iij. (=D. 26,2,23)

También resulta apropiado utilizar este sistema numeral desvinculado de la repetición del initium, para indicar la posición de la fuente dentro de su título. Por ejemplo:

${ }^{90}$ En contra de la exclusión, Lenel, Pal. II, cols. 1016 y 1018, frs. 2392 y 2409. En n.5 al primer fragmento resume las razones de Mommsen para excluir este texto, y deben extenderse también al otro.

${ }^{91}$ Bartol, Uersio Praefationis Editionis Maioris, cit. 11: «los compiladores no añadieron números ni a estos extractos ni a los títulos. Así pues, de los libros <que tenemos>, el Florentino no tiene esos números, y los Bononienses no tienen más que cuantos están a la vista; <en cambio>, el Napolitano y el Pommersfeldense tienen ciertamente números, pero aquél tiene los latinos, éste los griegos, colocados en el margen y de un tamaño menor. Además hay vestigios de los números griegos en el libro Berlinés. De todo esto se deduce que estos números también faltaron desde el principio en el corpus, y que comenzaron a añadirse prontamente para citar con más comodidad».

92 Kantorowicz, Die Allegationen im späteren Mittelalter, cit., 16. 
ff. de damno infecto l.iij. (=D. 39,2,3)

ff. de iure deliberandi l.iv. (=D. 28,8,4)

o este ejemplo que tomo de una cita de Petrus de Bellapertica (siglo XIII):

ff. de solutio. l. iij (=D. 46,3,3 pr. $)^{93}$

Asimismo cuando el fragmento ocupa la primera posición del título a menudo no se utiliza su initium sino que es designado con las abreviaturas $p r$. y princ. de principium, o l. prima:

ff. de S.P.R pr. (= D. 8,3,1)

ff. de dolo l. prima (D. 4,3,1 $)^{94}$

Y cuando el fragmento se aloja en la última, la penúltima o la antepenúltima posición de su título, generalmente es citado por las expresiones l. fin. fina. (finalis); l. ult. (ultima); l. p., pe., penu., penult. (penultima); l. antep., antepe., antepen., antepenu., antepenult (antepenultima) ${ }^{95}$ :

ff. de iure codicillorum l. antep. (= D. 29,7,18)

ff. de R.I. l.fin. (= D. 50,17,211)

ff. de B.P.c.t. l.p. $(=\mathrm{D} .37,4,20)$

ff. de albo scribendo l. ult. (= D. 50,3,2)

Si el título sólo contiene un único fragmento a menudo se indica mediante las expresiones una o un. (-ica, -ico), salvo que se cite un «§», pues entonces el un. suele omitirse ${ }^{96}$. Es el caso, por ejemplo, de D. 43,10,1 que se cita por los glosadores como

ff. de via publica \& si quid l. una

mejor que

ff. de via publica \& si quid l. Oi àstovouıкоі.

${ }^{93}$ Petrus de Bellapertica, Lectura Institutionum, Lugduny apud: Haeredis Simonis Vicentis, 1536 (hay una reimpresión Opera Iuridica Rariora VII, Bolonia 1972), IV,1,4-5, 317. Sobre esta obra de Pedro de Bellapertica véase LANGE, Römisches Recht im Mittelalter: die Glossatoren, I, cit., 563 y nt. 170, especialmente en relación a las tres ediciones: Paris 1512, 1514 y Lyon 1536.

${ }_{94}$ Petrus de Bellapertica, Lectura Institutionum, cit., IV,1,4-5, 317.

95 Thibaut, Über die Arten das Corpus Iuris allegiren zu Romani, cit., 210 y KaNTorowicz, Die Allegationen im späteren Mittelalter, cit., 17: «Ähnlich wurde die letzte, vorletzte, und vorvorletzte Stelle (Lex, Canon, Paragraph) oft, statt durch das Initium, durch ult. (oder fin.), p. oder pe. (-nultima, -mo), und antepe. Gekennzeichnet».

96 Thibaut, Über die Arten das Corpus Iuris allegiren zu Romani, cit., 223. También Kantorowicz, Die Allegationen im späteren Mittelalter, cit., 17: «Enthält der Titel oder sonstige Unterteil nur eine einzige Lex (Canon), so wird dies oft durch una oder un. (-ica, -ico) bezeichnet, und, wenn ein § daraus allegiert wird, das un. manchmal weggelassen». 
Si se pretendiera citar uno de sus parágrafos, al tratarse de un fragmento único, puede omitirse la abreviatura un. e incluso la referencia a la ley. Por ejemplo D. 43,10,1,3 se cita

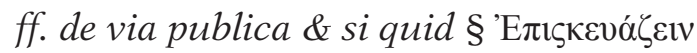

con preferencia a

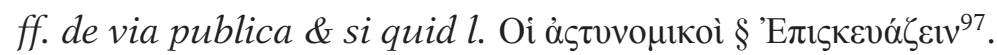

En otras ocasiones a la rúbrica y al signo de parágrafo le sigue simplemente el número de éste con omisión completa del fragmento único del título:

ff. de via publica \& si quid §.iiij. (= D. 43,10,1,4)

Los fragmentos se indican bien por su initium bien por el lugar que ocupan dentro de su título. En este último caso, las citas pueden seguir el modelo numeral o el ordinal. El primero sigue el criterio general, ya expuesto, para la expresión de cifras: la única o última « $i$ » es reemplazada por una « $j$ » y la cifra se encierra dentro de puntos salvo cuando precede a una abreviatura, en cuyo caso se aprovecha el punto de ésta ${ }^{98}$. El segundo identifica el fragmento con los términos prima, secundo/a, terzo/a, ... rara vez supera el sexto/a. Dos ejemplos tomados de citas de Petrus de Bellapertica:

ff. de solutio l. iij (= D. 46,3,3) ${ }^{99}$

ff. de dolo l. prima (= D. 4,3,1) $)^{100}$

Como es sabido los fragmentos generalmente suelen ir precedidos indistintamente por las abreviaturas l. (lex, lege o legis, más frecuente entre los glosadores) o c. (caput, más acostumbrado entre los humanistas). No debe confundirse la $l$. de lege con la de libro que en algunas ocasiones se abrevia también como $l i .{ }^{101}$. Ambas abrevia-

${ }^{97}$ En este ejemplo debe tenerse en cuenta que la rúbrica difiere entre las versiones de $F$ y $V$; he utilizado la de la primera pues la de la última es de via publica et itinere publico reficiendo.

${ }_{98}$ Como dice Thibaut, Über die Arten das Corpus Iuris allegiren zu Romani, cit., 210, los glosadores algunas veces incluyeron en la cita del Digesto el número del fragmento: ff. De rei vind. l.iiij. = D. 6,1,4. En otras ocasiones lo que incluyeron fue el número del parágrafo del fragmento. Por ejemplo ff. de rei vind. l. Julianus $\S$. $j$. = D. 6,1,17,1. En este mismo sentido Kantorowicz, Die Allegationen im späteren Mittelalter, cit., 17.

99 Petrus de Bellapertica, Lectura Institutionum, cit., 317.

100 Petrus de Bellapertica, Lectura Institutionum, cit., 316.

101 Kantorowicz, Die Allegationen im späteren Mittelalter, cit., 17: «Abgekürzt wurde, wie man sieht, lege (oder legis) durch l., es bedeutet dies manchmal auch libro, wofür jedoch korrekterweise li. gesetzt wird». 
turas, $l$. y c., están vacantes en muchas citas en las que los initia se identifican sólo por comenzar por letras mayúsculas:

ff. pro socio Nec praetermittendum (= D.17,2,57)

Sin embargo, salvo en el primer fragmento de un título, tanto la $l$. como la $c$. no se omiten cuando varias fuentes son citadas una a continuación de otra, pues sirven para separar las citas de los textos ${ }^{102}$. Como separador entre ellos también se utiliza et o \&. Los siguientes ejemplos de cita múltiple los tomo de Antonio Agustín ${ }^{103}$ :

c. pali 168. D. de verb. sign. \& c. Pali 16. D. de legat. 3. (= D. 32,56 y $50,16,168)^{104}$

c. autem 183 [in vulg. c. quod contra 141] \& c. quod vero $14 D$. de legib. (= D. 50,17, 183 y $1,3,14)^{105}$

c. quis sit fugitivus $17 \mathrm{D}$. de aedii. edict. \& c. qui ea mente $65 \mathrm{D}$. de furtis (= D. 21,1,17 y 47,2,65) $)^{106}$

Los glosadores y comentaristas casi siempre introducen las citas de los fragmentos con las locuciones ut o ut in o ut dixi. También con dicitur in o facit o arg. con la que se abrevia la palabra argumento. Dos ejemplos de Petrus de Bellapertica:

arg. ff. commo. l. si ut certo $(=\mathrm{D} .13,6,5,4)^{107}$

arg. ff. ad sille. l. tertia § si cum omnes (= D. 29,5,3,4)

En muchos casos la cita se engarza con la abreviatura de argumento legis ${ }^{109}$, es decir arg. $l$., de forma que es dependiente de un ablativo y se lee como un genitivo ${ }^{110}$, por ejemplo:

102 Kantorowicz, Die Allegationen im späteren Mittelalter, cit., 17.

${ }^{103}$ ReINOSO-BARBERo, El estudio de las geminaciones jurisprudenciales de Antonius Augustinus, cit., 8 .

104 Antonius Augustinus, Emendationum, cit., 1451: «Ceterae quoque partes si comparentur, apertiorem efficient utriusque capitis mentem. Quibus utroque loco additum Paulli caput est lib.4 ad Sabinum, c. pali 168. D. de verb. sign. \& c. Pali 16. D. de legat. 3».

${ }^{105}$ Antonius Augustinus, Emendationum, cit., 1451: «Caput autem 183 [in vulg. c. quod contra 141] \& c. quod vero 14 D. de legib. sunt ex lib. 54 Pauli ad edictum».

106 Antonius Augustinus, Emendationum, cit., 1453: «Illud apte divisum est, quod c. quis sit fugitivus $17 \mathrm{D}$. de aedii. edict. \& c. qui ea mente $65 \mathrm{D}$. de furtis. ex lib. 1 Ulpiani ad edictum aedilium, sumptum est. Utroque enim loco eadem ratio diversis exemplis adfertur».

107 Petrus de Bellapertica, Lectura Institutionum, cit., IV,1,4-5, 316.

108 Petrus de Bellapertica, Lectura Institutionum, cit., IV,1,4-5, 317.

109 Freiesleben, Programma juridicum de ratiocinatione ex argumento legis, Altdorf, 1730, 20.

${ }^{110}$ Kantorowicz, Die Allegationen im späteren Mittelalter, cit., 17. 
arg. l. facturus in opus ff. de O.J. = argumento legis facturus in opus Digestis de origine iuris (= D. 1,2,1)

Los fragmentos opuestos se señalan con las expresiones contra o fallit, como se ve en este ejemplo tomado de una cita de Jacobus Butrigarius (siglo XIV) ${ }^{111}$ que reproduce una glosa de Accursio (siglo XIII):

arg. contra .J: l. Paul § fin. (= D.20,1,29,3)

El texto principal a menudo es acompañado de la fórmula est casus legis ${ }^{112}$.

Un asunto diferente lo constituye la cita de los fragmentos de los libros 26 y 27 de Digesto procedentes del libro excusationum de Modestino escritos en letra griega. Estos textos griegos son leídos con mucha dificultad -o no son leídos- por los bononienses cuando aparece el Infortiatum probablemente en la primera mitad del siglo XII, por lo que son transpuestos al latín por Burgundio Pisano (1110$1194)^{113}$. Las vulgatas de peor calidad, algunas de las que Mommsen llama recentiores, sustituyen los fragmentos griegos originales por la versión latina burgundiona. Afortunadamente, cuando comienzan a realizarse en el siglo XVI las versiones impresas de las vulgatas, casi todas recuperan el texto griego e incluso algunas lo toman de $F$ vía las anotaciones que circulaban de Policiano, Antonio Agustín, Torelli y Metelo ${ }^{114}$. No obstante, se mantienen la traslación latina en lugar del texto original griego en algunas ediciones incluso tardías, como la de Freisleben de $1759^{115}$. Fuera como fuese, debe tenerse en cuen-

111 Jacobus Butrigarius, Commentaria Eruditissima, cit., comentario a D. 1,9,1.

${ }^{112}$ Kantorowicz, Die Allegationen im späteren Mittelalter, cit., 18.

${ }^{113}$ Hillner, Anhang IIII, p.35* zu Mommsen Editio maior; versio vulgata Modestinianorum (Dig. Lib. XXVI u. XXVII), en ZSS 123, 2006, 344-348, ofrece, sobre los libros 26 y 27 de Digesto, una übersetzung al alemán desde el latín del revelador cuarto additamenta del vol. I de la editio maior momseniana sobre las traducciones burgundionas de los textos griegos de D. 26 y 27.

${ }_{114}$ Brenkmann, Historia Pandectarum seu Fatum Exemplaris Florentini, Trajecti ad Rhenum, apud Guillelmo vanden Water, 1722, 292. Brenkmann facilita algunos pormernores de, por ejemplo, la edición de Hugo a Porta de 1551. Tomó pasajes de la Florentina vía Antonio Agustín a través de Metelo, antes de que Torelli tuviera preparada la edición de 1553. Por cierto, gracias a esa traición se conoce el contenido del famoso folio perdido de $F$ que, por fortuna, fue copiado por Antonio Agustín e incluido a hurtadillas en aquella edición de 1551. Al momento de redactar estas líneas se encuentra pendiente de lectura la prometedora tesis doctoral de JUAN LORENZO LORENZO -dirigida por José MARía COMA FORT- en la que se traduce al español esta capital obra de Brenkmann.

${ }^{115}$ Freisleben, Corpus Iuris Civilis Academicum, vol. I, Coloniae Munatianae, 1759. 
ta que un mismo fragmento puede dar lugar a dos o más diferentes citas, en griego y en latín. Por ejemplo, la cita de $F$ de D. 27,1,13,9 es

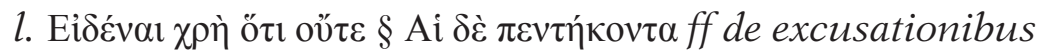

pero en las ediciones burgundionas es

l. scire oportet $\S$ quinquaginta vero dies ff de excusationibus ${ }^{116}$

que no coinciden a su vez con la derivada de la traducción krügeriana:

1. sciendum est § quinquaginta dies numerantur ff de excusationibus ${ }^{117}$

En los primeros ejemplares bononienses los textos griegos son copiados casi con garabatos pues los copistas ignoran por completo esa lengua. Algunos fragmentos son abreviados y otros son suprimidos. En este último caso la supresión es revelada con la abreviatura grec o con alguna otra similar. Sin embargo, en los libri recentiores, que reproducen el texto ordinario tal como se leía en los escolios de la época de Accursio, los fragmentos griegos, cuando no son sustituidos por la interpretación latina de Burgundio Pisano, son suprimidos por completo ${ }^{118}$.

Alguna información sobre esta traducción de Burgundio la da Savigny $^{119}$. La primera noticia sobre el particular se encuentra en el codex Bambergensis (D. I.6 del siglo XIII) del Digestum vetus que contiene una glosa al fragmento griego de D. 14,2,9 perteneciente al título de la lex Rhodia de iactu, en la que se lee: translatum pisis a burgundione Bernardo cremonensi. Fitting ${ }^{120}$ añade a este dato otra glosa existente en un manuscrito del Infortiatum, comprado por d'Ablaing (profesor de la Universidad de Leiden) en abril de 1889 poco antes de su muerte ${ }^{121}$. Se trata de una glosa a D. 26,3,1 en el que existe una nota novena que dice: 9 § lex Graeca hic deficit. set translatata (!) fuit bernardo cremonensi. a burgundione ${ }^{122}$. Savigny piensa que Burgundio

116 NicOlinI \& D'AMICO, Indices corporis iuris civilis iuxta vetustiores editiones cum criticis collatas, pars III (index paragraphorum), cit., 383 indica que D. 27,1,13,9 de la edición crítica se corresponde con D. 27,1,15 de la edición vulgata.

${ }^{117}$ KRÜGER, CIC, vol. I., cit., 395.

118 Mommsen, Praefatio, cit., XXXXV y XXXXVI.

${ }^{119}$ SAVIGNY, Geschichte des römischen Rechts im Mittelalter, cit., 3, 336 nt. 6.

${ }^{120}$ FitTing, Bernardus Cremomensis und die lateinische Übersetzung des Griechischen in den Digesten, en Sitzungsberichte der königliche preussischen Akademie der Wissenschaften zu Berlin, 35, 1894, 813-822.

${ }^{121}$ FitTing, Bernardus Cremomensis, cit., 813: «In der Universitäts-Bibliothek zu Leiden befindet sich zu Zeit eine Handsschrift des Infortiatum, welche der dortige Professor D'ABLAING im April 1889 ganz kurz vor seinem Tode käuflich erwarb».

${ }^{122}$ FitTing, Bernardus Cremomensis, cit., 815: «Ferner war es ihm darum zu 
es el epíteto de Bernardus Cremonensis, mientras que Fitting sostiene que la traducción es realizada por Burgundio para Bernardo, opinión que es compartida por Kantorowicz ${ }^{123}$ y, después, por Gualazzini ${ }^{124}$.

Por último, si un fragmento de Digesto se encuentra geminado ${ }^{125}$, los autores a menudo añadían a la cita las expresiones cum suis concordantiis o cum similibus ${ }^{126}$. El siguiente ejemplo procede del Ordo Iudiciarius Scientiam (siglo XIII) ${ }^{127}$ :

ff. de diversis regulis l. Si librarius, cum suis concordantiis (= D. 50,17,92)

Accursio califica el fragmento geminado como caput unum altero absolutius, Bártolo de Saxoferrato decía verbo ad verbum duplari, y Antonio Agustín quam multa in iure totidem verbis scripta sint. El término "geminación» en el sentido que hoy tiene en la romanística, como he escrito en otro lugar, lo introduce Prateio en el siglo XVI ${ }^{128}$.

\section{III.5. Parágrafos}

Ni la Florentina ni el resto de los códices de Digesto de su época dividen los fragmentos largos ${ }^{129}$. Sin embargo a menudo aparecen en

thun, den Digestentext auf Grund des Pisanus vollständig, vmd also auch in den griechischen Partien, diese jedoch in einer allgemein zugänglichen Gestalt, d. h. in lateinischer Übersetzung, zu geben. Da er aber selbst ohne Zweifel nicht genügend griechisch verstand, so liefs er sich das Griechische in den Digesten, soweit nicht etwa schon eine lateinische Übersetzung vorhanden war, von Burgundio übersetzen. Diese interessante Bereicherung unseres Wissens, die Thatsache also, dass Burgundio die übersetzung für den Bernardus gemacht hat, ergibt sich aus folgender Randbemerkung f. 9 e. 3 zu L. 1 D. de confirm. tut. 26, 3, von der sich, ebenso wie bei anderen griechischen Stellen, in der Leidener Handschrift blofs die Inscription findet mit dem Vermerke, dass die Stelle griechischen Text habe, hier ausnahmsweise auch der Anfang der Stelle in griechisch sein sollender Schrift: 9 § lex Graeca hic deficit. set translatata (!) fuit bernardo cremonensi. a burgundione».

${ }^{123}$ KANTOROWICZ, Über die Entstehung der Digestenvulgata, en ZSS, 30, 1909, 207 nt. 28.

${ }^{124}$ GualazzInI, Contributi alla storia della scuola giuridica cremonese nel XII e XIII secolo, en Studi di storia e diritto in onore di Arrigo Solmi, I, Milán, 1940, 94.

${ }^{125}$ ReInoso-Barbero, El estudio de las geminaciones jurisprudenciales de Antonius Augustinus, cit., e ID., Pardulphi Pratei: Geminationum, cit., sobre las distintas fórmulas empleadas en la literatura de los siglos XII al XVI para identificar las geminaciones jurisprudenciales.

${ }^{126}$ Kantorowicz, Die Allegationen im späteren Mittelalter, cit., 18.

127 WaHRmund, Quellen zur Geschichte des römisch-kanonischen Processes im Mittelalter, cit., 22; concretamente la cita se encuentra en el caput IX titulado Replicationes contra praemissas exceptiones.

${ }^{128}$ ReInoso-Barbero, "Geminationum» de Prateio, cit., 3.

${ }^{129}$ Mommsen, Praefatio, cit., XI: «Capitum longiorum diuisiones in paragraphos 
ellos signos en los lugares donde termina una idea y comienza otra, con lo que facilitan de alguna forma el trabajo que luego se hará. Los primeros en comenzar una tenue división de los fragmentos son los Basílicos, aunque limitada sólo al principio de algunos textos. Mommsen $^{130}$ da el siguiente ejemplo:

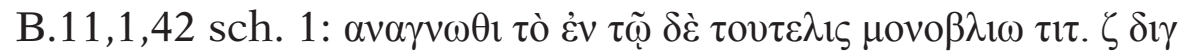

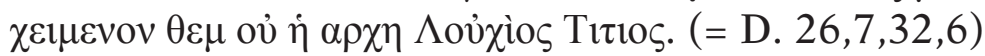

Es a partir del siglo XI cuando comienza la división temática de los fragmentos en lo que hoy llamamos parágrafos. Los bizantinos los denominan $\theta \varepsilon \dot{\mu} \mu \alpha \tau \alpha^{131}$ y los glosadores responsa ${ }^{132}$.

Los parágrafos son representados de varias formas en las citas de Digesto, entre las que destaca el grafema «§» que precede al initium. Véase este ejemplo de Cino da Pistoia (siglo XIII) ${ }^{133}$ :

ff. commod. l. si ut certo $\S$ quod vero (= D. 13,6,5,4)

o estos otros, de la misma época, de Petrus de Bellapertica ${ }^{134}$ :

ff. commo. l. si ut certo $\S$ plane (=D. 13,6,5,4)

ff. de administra. tut. l. tutor $\S$ primo (=D. 26,7,7 pr.).

ff. de carbo.edict. l. prima $\S$ sed et si quis (=D. 37,10,1,5)

o éstos de Jean de Coras, llamado Corasius (s. XVI) ${ }^{135}$ :

l. si ut certo $\S$ nunc videndum, ff. commod. (=D. 13,6,5,4)

l. eum qui $\S$ is autem ff. de furt. (=D. 47,2,14,3)

... Latini certe codices nullo tempore admiserunt»; cfr. BARTOL, Uersio Praefationis Editionis Maioris, cit. 13.

${ }^{130}$ Mommsen, Praefatio, cit., XI; cfr. Bartol, Uersio Praefationis Editionis Maioris, cit. 13 .

${ }^{131}$ Mommsen, Praefatio, cit., XI: «... paragraphos quae nobis dicuntur, $\theta \varepsilon ́ \mu \alpha \tau \alpha$ uero Byzantiis»; cfr. BARTOL, Uersio Praefationis Editionis Maioris, cit. 13.

${ }^{132}$ Kantorowicz, Die Allegationen im spateren Mittelalter, cit., 19: «... und das Initium des Paragraphen (der auch responsum genannt wird)».

${ }^{133}$ Cino Da Pistoia, In Codicem et aliquot titulos primi Pandectorum tomi, id est Digesti veteris, doctissima commentaria ... Sigismund Feyerabendt, Francoforti ad Moenum, 1578 (hay una reimpresión de la editorial Bottega d'Erasmo, Turín, 1964), 275: «Nam pone, quod res locatoris erant graves, forte quia in horreis habebat servum vel similia, res conductoris erant leves et viliores. Isto casu et similibus non est praesumptio sufficiens, ut ff. commod. l. si ut certo § quod vero».

134 Petrus de Bellapertica, Lectura Institutionum, cit., IV,1,4-5, 317.

135 IoANnIs Corasir, Miscellaneorum juris civilis libri septem, Coloniae Agrippinae: Apud Theodorum Baumium, 1581, I, 15: «Latam autem culpam non praestet depositarius: sed de solo dolo teneatur, l. si ut certo, § nunc videndum, ff. commod. l. eum $q u i, \S$ is autem ff. de furt, in qua sententia est Ioan. Igneus praeses Rhotomagen». 
Pero también se usan con frecuencia, como acertadamente destaca Spangenberg ${ }^{136}$, el glosema « $\theta »$ así como la abreviatura $\theta \varepsilon \dot{\mu} \mu ., \theta \varepsilon \mu$. o $\theta \varepsilon \mu \alpha$. con los que se simboliza $\theta \varepsilon ́ \mu \alpha \tau \alpha$. Éstos signos se popularizan sobre todo a partir de su utilización por Gregorio Meltzer en la praefatio de la edición Haloandrina. Los siguientes ejemplos son citas de Pardulpho Prateio (siglo XVI) ${ }^{137}$ :

$\theta \varepsilon \mu .1$ cap. 31 lib. 12 [l.cum fundusßservum tuum D. Si cert.pet.] (=D. $12,1,31,1)^{138}$

$\theta \varepsilon \mu .1$ cap. 24 lib. 19 tit. 1 [l. si servus $24 \S 1$ D. de act. empt.] (=D. $19,1,24,1)$

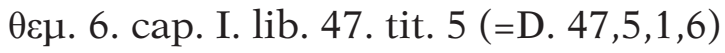

En muchos mmss. el comienzo de los parágrafos se distingue por la alteración del formato de las letras. Los parágrafos, igual que sucede con los fragmentos, suelen ser citados en caso ablativo ya se utilice su initium o bien la posición que ocupan dentro de su sección ${ }^{139}$. En este último supuesto a veces se añade una «» ${ }^{\circ}$ superíndice $^{140}$ al final de la cita:

ut ff.de Legibus Senatusque l. de quibus $\S . j^{\circ}$. (=D. 1,3,32,1)

Para citar un principium se utilizan las abreviaturas $p r$. o in princ. pero también la expresión initium vero. Dos ejemplos tomados de citas de Antonio Agustín ${ }^{141}$ :

Initium vero $c$. in ambiguis 85 D. de reg. jur. (= D. 50,17,85 pr.)

c. miles 6 in princ. D. de re jud. (= D. 42,1,6 pr.)

${ }^{136}$ SPANGENBERG, Einleitung in das römisch-justinianeische Rechtsbuch, cit., 166 nt. 13, recuerda que los parágrafos se citan como $\theta$. o $\theta \dot{\mu} \mu a .$, entre otros lugares, en la praefatio de Haloandro.

${ }_{137}$ PARdulphi PrateI, Jurisprudentiae mediae libri IV, Lugduny: Apud G. Rovillium, 1561; he utilizado la edición de EvERARDI OTTONIs, Thesausurus juris romani, III, Basileae 1744, 505-613. En el caput CXXVII dice: "Bartolus Saxoferratius foelicissimi, feracissimique vir ingenii observavit $\theta \varepsilon \mu .1$ cap. 31 lib. 12 [l. cum fundus $31 \S$ servum tuum I D. Si cert. pet.] \& $\theta \varepsilon \mu .1$ cap. 24 lib. 19 tit. 1 [l. si servus 24 \& 1 D. de act. empt. ubi Bartol.] de verbo ad verbum (sic enim ipse loquitur) duplari"

${ }_{138}$ Reinoso-Barbero, "Geminationum» de Prateio, en e-Legal History Review, 15, 2013, 14.

139 ThiBaut, Über die Arten das Corpus Iuris allegiren zu Romani, cit., 210.

${ }^{140}$ Kantorowicz, Die Allegationen im späteren Mittelalter, cit., 17, propone el siguiente ejemplo de cita en ablativo que se lee como genitivo: «arg. 1. servus in opus ff. de penis = argumento legis servus in opus Digestis de penis (D. 48, 19, 34)».

${ }^{141}$ Antonius Augustinus, Emendationum, cit., 1451 y 1453 respectivamente. Cfr. Reinoso-BARBero, El estudio de las geminaciones jurisprudenciales de Antonius Augustinus, cit., nt. 38. 
Para facilitar la localización de otras partes del texto en parágrafos largos, las citas se valen de expresiones tales como circa, medium, in fin. o in fine, con las que aluden, respectivamente, a una posición inicial o próxima al principio, en medio o al final del texto. Así mismo, para indicar una frase exacta se emplean las abreviaturas de versiculo: ver. o vers. seguidas de las palabras por las que comienza. Un ejemplo tomado de la Quaestio secunda del caput CXII de la Suma aurea de Guillermo de Drogheda (siglo XIII) ${ }^{142}$ :

ut ff quae res pignori obligari non possunt l. Aristo, in fin. (=D. 20,3,3)

Esta terminología es heredada por los glosadores de los antecessores ${ }^{143}$, y sigue siendo hoy en día correcta. Feenstra \& Rossi ${ }^{144}$, en su Index adbreviationum et de modo citandi fontes, bajo el título «De modo citandi fontes per partes, leges, capitula, etc» recuerdan que las citas a menudo difieren no poco en cada una de las fuentes, por lo que proponen seguir siempre una regla general: las citas deben realizarse descendiendo desde la parte mayor a la menor de la fuente, según el orden de lectura. De acuerdo con este orden consabido, se cita primero el libro, el título, luego la ley y, en su caso, el parágrafo, expresados siempre mediante números de acuerdo con las divisiones y subdivisiones de las ediciones críticas de los libros, si las hay. Ahora bien, sugieren ${ }^{145}$ que cuando sea necesario por la longitud del texto, se pueden utilizar aquellas mismas clausulas empleadas por los glosadores: in principio, circa medium, in fine, o similar. Por ejemplo, dicen, l. 'Caius', in princ. o vers. 'Titius'. Así mismo sientan la regla de que cuando no coincide el texto de las ediciones antiguas con el de las ediciones críticas, se utiliza la numeración de estas últimas añadiendo delante del número la palabra nunc y, después del número, in principio circa medium,

${ }^{142}$ WAHRMUnd, Quellen zur Geschichte des römisch-kanonischen Processes im Mittelalter, II, I, Innsbruck, 1913, 108.

${ }^{143}$ Mommsen, Praefatio, cit., X-XI.

${ }^{144}$ FEENSTRA \& RosSI, Index adbreviationum et de modo citandi fontes, en IRMA I/1 a-d, Milán, 1961, 25: bajo el título «DE MODO CITANDI FONTES PER PARTES, LEGES, CAPITULA, ETC» indica: «Quia, apud nostrae aetatis scriptores, citationes partium seu legum seu capitulorum etc. singularum fontium non parum saepe differunt, hanc regulam generalem tradimus: citationes a parte maiore ad minorem uniuscuiusque fontis, in qua locus citandus legitur, procedant. Videlicet secundum hunc ordinem: primum inscriptio fontis afferatur, dein eius divisiones et subdivisiones, e.g. pars, liber, titulus, capitulum seu lex, paragraphus, versiculus; quae autem divisiones et subdivisiones per numeros secundum criticas editiones, si quae sint, indicandae sunt».

${ }^{145}$ FeENSTRA \& Rossi, Index adbreviationum et de modo citandi fontes, cit., 25: «Si qui locus autem seu versiculus citandus propria numeratione careat, post numerum legis vel capituli, ubi locus ille legitur, addendum est "in principio", "circa medium", "in fine”, vel similia: e.g. "l. 'Caius', in princ.” vel "vers. 'Titius'“”. 
in fine. Por ejemplo ${ }^{146}$, para expresar que un fragmento de la vulgata se encuentra en la primera mitad del fragmento anterior de la edición crítica:

ff. De alien. ind. mut. cau. facta, l. Non solum (= vulg. D. 4,7,5 = D. 4,7, nunc 4 circa mediana)

Según Mommsen, la utilización de estas expresiones (circa, medium , ...) es muy antigua y se remonta hasta el antecessor Juliano. Dice que Juliano, al citar el Digesto, casi siempre prescinde de los números, unas veces indicando el pasaje en el título (e. c. circa media loca), y otras veces escribiendo el nombre del autor: nam in digestis citandis excepto Iuliano antecessore, qui fere a numeris abstinet locum in titulo modo aliter significans (e. c. circa media loca), modo auctoris nomen adscribens ${ }^{147}$.

No es frecuente encontrar citas literales de textos extensos en las obras de los glosadores. Sin embargo las citas extensas son muy corrientes entre los comentaristas. En el renacimiento las citas literales se reducen generalmente a frases de unas pocas palabras. Cuando se producen esas citas literales, suelen ser introducidas por las expresiones $i b i^{148}$ (glosadores) o incipit ... ibi (comentaristas) o alguna otra similar. Los comentaristas heredan esta forma de citar y utilizan constantemente la fórmula

in glo. quae incipit [...] ibi [...]

En los primeros corchetes se incluyen las primeras palabras de la glosa que se quiere citar y en los segundos el final del texto con lo que se consiguen citas literales muy extensas. Así, por ejemplo, para comentar la glosa «i» de D. 1,9,1 del Digestum vetus se dice in glo. quae incipit [Privilegio] ibi [item in tutore], con lo que en realidad se dice: privilegio sexus: ut .s. de statu hominum .l. in multis prodest autem ... ut .C. qui bo. cede. poss. l. fin item in tutore. Algunos otros ejemplos que, como el anterior, tomo de citas contenidas en los comentaria de Jacobus Butrigarius (siglo XIII-XIV) ${ }^{149}$ :

in glo. quae incipit [imo quandoque] ibi [Auth. praeterea] (com. D. 1,8,10) in glo. quae incipit [duo fuerunt in fi.] ibi [Paedius:] (com. D. 1,8,11)

${ }^{146}$ FeEnSTRa \& Rossi, Index adbreviationum et de modo citandi fontes, cit., 25: «Si autem locus seu versiculus ille in mss. vel antiquis editionibus sub eodem numero quo in criticis editionibus non legatur, semper numeratione criticae editionis utendum est; addendo, ante numerum, "nunc" et, post numerum, "in principio" "circa medium", "in fine" (e.g.: locus in mss. citatus "ff. De alien. ind. mut. cau. facta,l. Non solum" "-et in vulgata numeratus «D. 4, 7, 5"- citandus est, secundum criticam editionem, “D. 4, 7, nunc 4 circa mediana")».

${ }^{147}$ Mommsen, Praefatio, cit., X-XI.

${ }^{148}$ Kantorowicz, Die Allegationen im späteren Mittelalter, cit., 17.

149 Jacobus Butrigarius, Commentaria Eruditissima, cit., 31. 
in glo. quae incipit [aliquam] ibi [habet locum quod hic \& c.] (com. D. 1,9,2) in glo. quae incipit [.f.ab alio] ibi [arg. contra .J. l. Paul § fin.] (com. D. 1,9,1)

Creo haber resumido en estas líneas la información fundamental para poder interpretar adecuadamente las diversas formas de citar los pasajes de Digesto que se emplean por las cinco generaciones de glosadores de los siglos XI al XIII, por los comentaristas de los siglos XIII al XV y los humanistas a partir del siglo XVI. 